\title{
The epigenetic processes of meiosis in male mice are broadly affected by the widely used herbicide atrazine
}

\author{
Aurore Gely-Pernot ${ }^{1 \dagger}$, Chunxiang Hao ${ }^{1 \dagger}$, Emmanuelle Becker ${ }^{1}$, Igor Stuparevic ${ }^{1,3}$, Christine Kervarrec ${ }^{1}$, \\ Frédéric Chalmel ${ }^{1}$, Michael Primig ${ }^{1}$, Bernard Jégou ${ }^{1,2}$ and Fatima Smagulova ${ }^{1 *}$ (i)
}

\begin{abstract}
Background: Environmental factors such as pesticides can cause phenotypic changes in various organisms, including mammals. We studied the effects of the widely used herbicide atrazine (ATZ) on meiosis, a key step of gametogenesis, in male mice.

Methods: Gene expression pattern was analysed by Gene-Chip array. Genome-wide mapping of H3K4me3 marks distribution was done by ChIP-sequencing of testis tissue using Illumina technologies. RT-qPCR was used to validate differentially expressed genes or differential peaks.

Results: We demonstrate that exposure to ATZ reduces testosterone levels and the number of spermatozoa in the epididymis and delays meiosis. Using Gene-Chip and ChIP-Seq analysis of H3K4me3 marks, we found that a broad range of cellular functions, including GTPase activity, mitochondrial function and steroid-hormone metabolism, are affected by ATZ. Furthermore, treated mice display enriched histone H3K4me3 marks in regions of strong recombination (doublestrand break sites), within very large genes and reduced marks in the pseudoautosomal region of X chromosome.
\end{abstract}

Conclusions: Our data demonstrate that atrazine exposure interferes with normal meiosis, which affects spermatozoa production.

Keywords: Meiosis, Double-strand breaks, Gene-Chip, ChIP-Seq, H3K4me3, Atrazine

\section{Background}

Environmental factors can alter DNA methylation and epigenetic modifications in the germline [51, 90]. We studied the effects of the widely used herbicide atrazine (ATZ) on meiosis. In many countries, ATZ is the most common contaminant detected in rivers [19, 72, 92]. ATZ residues are even detected in soil and aqueous environments in countries where it has been banned [59, 102, 103]. Low levels of ATZ metabolites in pregnant women are associated with low birth weight $[16,61]$. In mammals, ATZ is metabolized by several groups of xenobiotic-metabolizing enzymes. The metabolism of ATZ interferes with oxidative phosphorylation and cytochrome P450 function, resulting in decreased oxygen consumption [10, 14, 39, 47]. ATZ is

\footnotetext{
* Correspondence: fatima.smagulova@inserm.fr

${ }^{\dagger}$ Equal contributors

${ }^{1}$ Inserm U1085 IRSET, 263 Avenue du Général Leclerc, 35042 Rennes, France Full list of author information is available at the end of the article
}

known to alter reproductive processes in rodents $[96,101]$, reptiles [18], birds [104], goats [81], amphibians [28-30] and fish $[63,69]$. ATZ targets many tissues, including the testes $[67,68,101]$, ovaries $[8,17,41,52]$, brain $[5,7]$, liver $[25,36,38,78]$. The effects of ATZ on reproduction have been extensively studied; however, the effect of ATZ on meiosis has not been elucidated.

Meiosis is the division of germ cells and is essential for the production of haploid gametes. In most organisms, homologous recombination (HR) is important for the proper segregation of chromosomes during meiosis. HR predominantly occurs in discrete areas of the genome known as recombination hotspots. Histone $\mathrm{H} 3$ trimethylation at lysine 4 (H3K4me3) by PRDM9 methyltransferase is indispensable for the proper formation of doublestrand breaks (DSBs) throughout the genome, except in the pseudoautosomal region (PAR) of $\mathrm{X}$ chromosome [12]. Germ cells lacking PRDM9 are unable to repair 
DSBs at the pachytene stage of gametogenesis, and knock-out mice are infertile in both sexes [27, 53]. It has also been shown that environmental pollutants affect HR both in male and female. The first study illustrating the effects of environmental exposure on meiosis was the bisphenol A (BPA) treatment study, in which the authors showed that embryonic exposure to BPA causes meiotic anomalies, which lead to aneuploidy in adult female mice [34]. Importantly, meiotic effects in animals were induced by environmentally relevant doses of BPA [34]. BPA exposure of adult rat delays meiosis initiation and induces accumulation of meiotic DNA DSBs in the late meiotic stage [48]. In nematodes BPA exposure also results in impaired chromosome synapsis and disruption of meiotic doublestrand break repair (DSBR) progression of C. elegans [4].

We hypothesized that ATZ may also alter meiosis because it reduces sperm number and changes testis morphology in animals $[1,101]$. Here, we studied the mechanisms by which ATZ affects meiosis in mice. We showed that exposure to ATZ increases testosterone levels and reduces the number of spermatozoa in epididymis, causing a delay of meiosis. Using Gene-Chip and ChIP-Seq analysis of H3K4me3 marks, we found that a wide range of cellular functions, including GTPase activity, mitochondrial function and steroid-hormone metabolism, are affected by ATZ. Furthermore, histone H3K4me3 marks are enriched in treated mice in regions of strong recombination (DSB sites) within very large genes and reduced at the PAR region of the $\mathrm{X}$ chromosome. We therefore propose that ATZ disrupts normal meiosis.

\section{Results}

\section{Experimental design}

We treated adult male mice with ATZ at a concentration of $100 \mathrm{mg} / \mathrm{l}$ in water for three weeks and followed with two weeks without treatment to cover one full round of spermatogenesis (35 days). Given that mice drink approximately $5 \mathrm{ml}$ of water per day, we estimate that the average intake of ATZ was approximately $25 \mathrm{mg} / \mathrm{kg} /$ day. This dose is relatively low compared to that used previously $[1,67,96]$. We chose this dose of ATZ because doses higher than $50 \mathrm{mg} /$ $\mathrm{kg} /$ day are known to change the weight of internal organs and are considered as toxic [101]. To study the effect of ATZ on the first wave of spermatogenesis, we treated newborn animals from postnatal day 1 through day $20 \mathrm{dpp}$ by administering ATZ suspended in oil to the lactating dams at a dose of $25 \mathrm{mg} / \mathrm{kg} /$ day.

Low levels of atrazine do not affect testicular morphology and cell viability

After treatment, the mice were euthanized, and reproductive organs were dissected. We measured the organs and body weights of treated and control animals. We found that the body weight and reproductive organs (testes, epididymis and seminal vesicles) were not affected at this dose (data not shown). To evaluate morphological changes in seminiferous tubules caused by ATZ, we analyzed paraffin-embedded sections stained with hematoxylin and eosin and compared matching stages from treated and control animals. The morphological analysis did not reveal any significant changes in either the seminiferous tubules or the epididymis (Additional file 1: Figure S1 (A-D)). However, we could not exclude small changes in the proportion of cells, which are difficult to distinguish by this method. We verified cell populations by staining with propidium iodide (DNA-staining agent) and sorting by FACS and we comcluded that cell populations were not significantly affected by this treatment (Additional file 1: Figure S2 (A-E)). To examine whether the number of germ or Sertoli cells had changed, we immunostained testicular tissue with antibodies specific for undifferentiated spermatogonial stem cells (PLZF) and Sertoli cells (GATA1) (Additional file 1: Figure S3 (A-B)). We found that treatment did not significantly alter the number or proportion of those cell types (Additional file 1: Figure S3C). To evaluate the rate of apoptosis, we performed TUNEL assays using the In Situ Cell-Death Detection kit. We did not detect significant changes in the rate of apoptosis in adult ATZ-treated mice compared to control (Additional file 1: Figure S3D). Thus, treatment with a relatively low dose of atrazine does not affect organ weight or the cell populations within seminiferous tubules.

\section{Decreased sperm count and serum testosterone levels in ATZ-treated mice}

One essential metric of reproductive state is the number of spermatozoa per epididymis. To evaluate the effect of ATZ, we counted spermatozoa in the epididymis of treated and control mice. We found that ATZ-treated mice had a significantly lower sperm count (68\%) than untreated animals (" $p<0.05 ; n=10$, Fig. 1a). To assess endocrine function after treatment, we measured serum levels of testosterone and follicle-stimulating hormone (FSH). We found that serum testosterone was 3.4 times lower in treated animals $(* p<0.05, n=10)$, while the level of FSH was not significantly affected ( $p=0.06, n=10$, Fig. $1 b)$. Our data show that a relatively low dose of atrazine decreases sperm counts and serum testosterone levels.

Analysis of the synaptonemal complex reveals delayed meiosis We hypothesized that a decrease in sperm count might reflect defects in meiotic progression or spermiogenesis. We thus asked whether ATZ negatively affects the meiotic stages of spermatogenesis. To analyze meiotic progression in treated mice, we performed surface spreads from testis tissue and analyzed synaptonemal-complex (SC) formation. The SC is formed exclusively during prophase 1 of meiosis, and its major role is to bring the chromosomes together [32]. Prophase I is subdivided into several sub-stages 

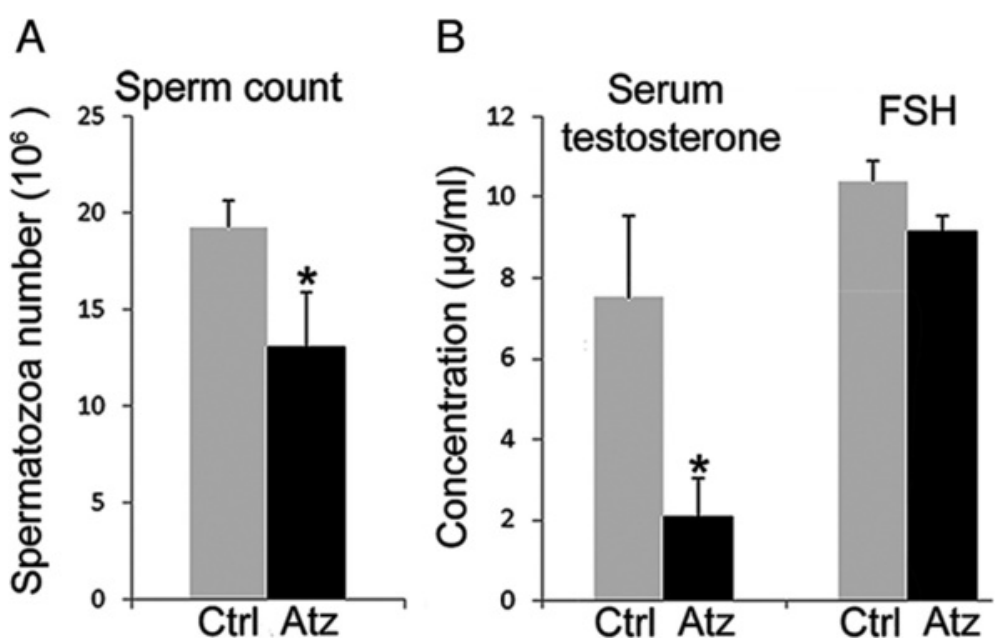

Fig. 1 Low-dose ATZ treatment decreases spermatozoa numbers and testosterone levels. a The number of spermatozoa in the epididymis decreased. $\mathbf{b}$ The amount of testosterone in the serum decreased; $n=10 /$ group; values are means $+/-S D$, while FSH was not significantly affected ( ${ }^{*} p<0.05, n=10 /$ group, values are means $+/-S D$ )

(leptotene, zygotene, pachytene, diplotene and diakinesis). We immunostained the surface cell spreads with antibodies against SYCP3 (marker of synaptonemal complex proteins) and $\gamma \mathrm{H} 2 \mathrm{AX}$ (stains chromatin at DSB sites) and then classified cells into meiotic substages (Fig. 2a) as previously described [50, 62], (see Materials and Methods for more details). During the leptotene phase, there is an increase in the number and intensity of $\gamma \mathrm{H} 2 \mathrm{AX}$-positive domains throughout the nucleus. In the zygotene stages, the number of $\gamma \mathrm{H} 2 \mathrm{AX}$ domains and the intensity of $\gamma \mathrm{H} 2 \mathrm{AX}$ staining decreased, as the staining was concentrated over the chromatin. At the early pachytene stage, $\gamma \mathrm{H} 2 \mathrm{AX}$ had almost disappeared from the chromatin of the autosomes, but there were still some visible traces of marks on autosomes, and marks appeared to cover the sex chromosomes. At the late pachytene stage, $\gamma \mathrm{H} 2 \mathrm{AX}$ was detected only at the sex chromosomes. The proportions of prophase I substages detected in control mice were similar to those detected by other authors $[13,20]$. However, we found that the number of early stage spermatocytes increased in ATZ-treated animals (2.4 times the number observed in the zygotene and 1.9 times that observed in the early pachytene stages), while the late stages decreased (1.8 times fewer than observed in the diplotene stages) (Pearson's Chi-squared test, $p<$ 2.2e-16) (Fig. 2b). In control mice, the largest fraction of spermatocytes was in the late pachytene stage, where $\gamma \mathrm{H} 2 \mathrm{AX}$ markers were detectable only in sex chromosomes (Fig. 2c). In ATZ-treated animals, the majority of spermatocytes showed patterns of $\gamma \mathrm{H} 2 \mathrm{AX}$ staining typical of early stages (Fig. 2c). We performed quantitative analysis of early pachytene cell fractions in control and treated mice, and we detected three major defects in ATZ-treated mice: (1) incomplete synapsing of one or two chromosomes, which was often detected together with the formation of branched chromosome structures; (2) sexbody defects (sex chromosomes with very long chromosomal axes (Additional file 1: Figure S4A). We found that the number of cells with incomplete synapses increased 3.1 times in treated cells compared to untreated cells, the number of cells with sex-chromosome defects increased 3.6 times (Additional file 1: Figure S4B).

The performed analysis of immunostaining pattern of $\gamma \mathrm{H} 2 \mathrm{AX}$ marks helped us to evaluate the meiotic progression, however, we do not exclude the fact that our observation is not perfect due to the possibility that meiosis in some cells is deregulated and that the stages could not be defined exactly. Our analysis is designed to observe the general view of meiotic progress. We complete this finding by analyzing meiotic progress during the first wave of spermatogenesis (see section below).

Taken together, our data show that ATZ has an effect on meiotic progression and increases the number of synapsing defects.

\section{ATZ treatment delays meiotic progression due to persistence of DSBs}

We next asked whether the increase in early stage meiotic cells occurred due to the persistence of DSBs breaks. Chromosomes undergo DSB formation at the leptotenezygotene stage. At this stage, a maximal number of DSBs can be detected by staining surface spreads with an antibody against DMC1, which is a DNA-binding protein of DSBs. We found that the number of cells with DMC1 foci increased with ATZ treatment (Fig. 3a). Most of the cells positive for DMC1 in ATZ-treated animals had foci at the sex chromosomes. The increase in the number of DMC1positive cells with treatment could be the result of inefficient repair of DSBs in sex chromosomes. 


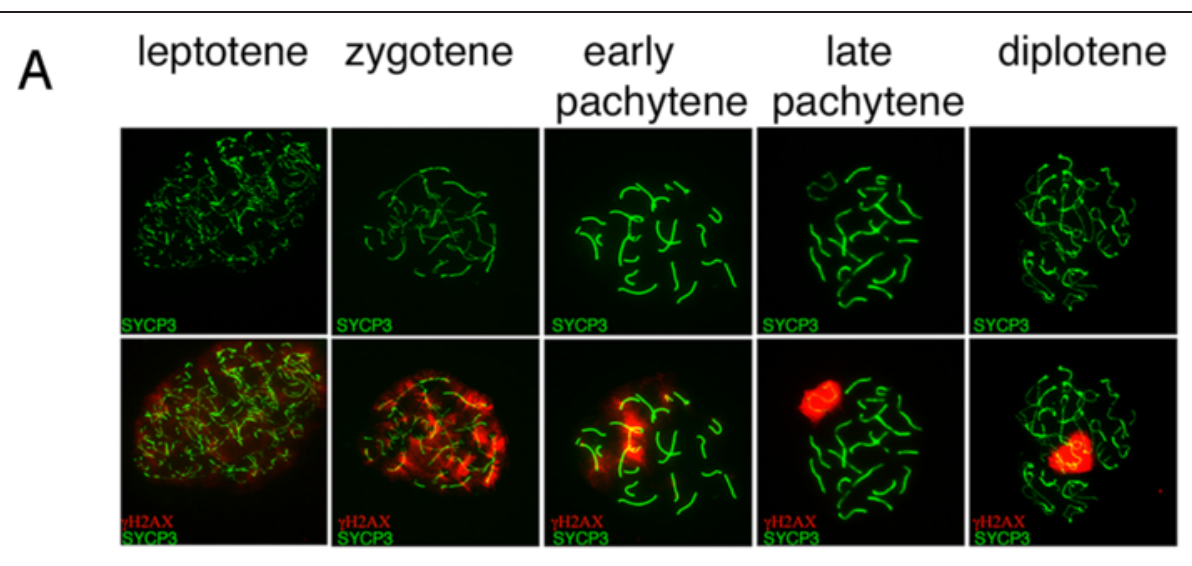

B

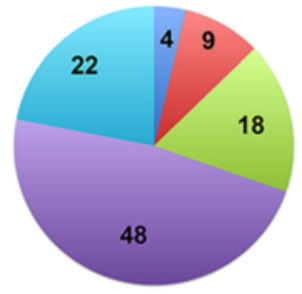

C
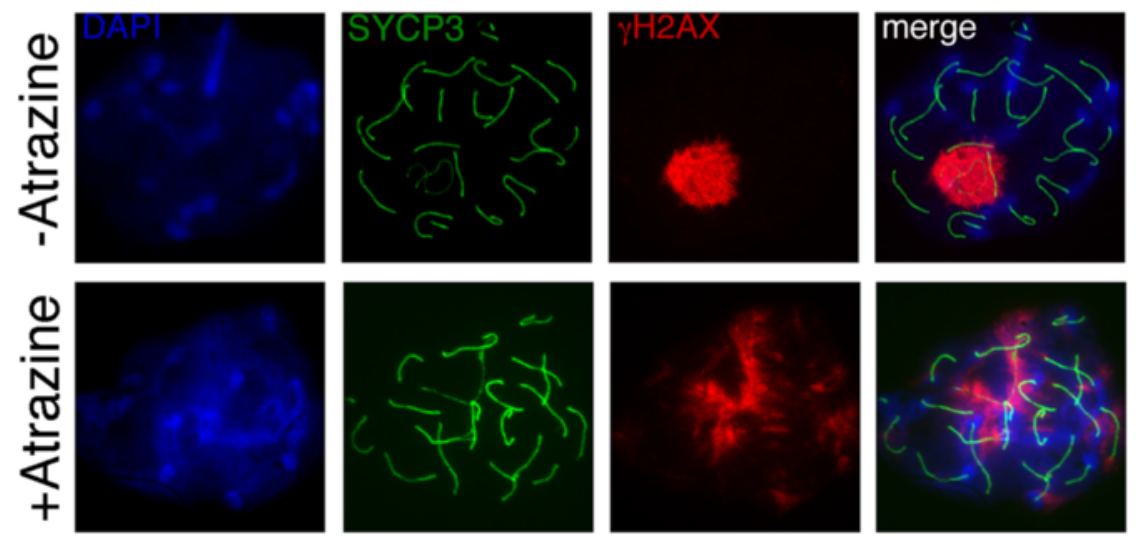

Fig. 2 Atrazine causes delayed meiosis in mice. a $\mathrm{YH} 2 \mathrm{AX}$ staining changes during meiotic prophase I substages. b The distribution of meiotic substages in control (left panel) and ATZ-treated (right panel) mice; 600 cells from control and treated mice were classified according to $\mathrm{YH}$ 2AX and SYCP3 staining. Note that the number of spermatocytes in the zygotene and early pachytene stages is increased in ATZ-treated animals, while the number of spermatocytes in the late stages decreased. c Surface spreads from control and ATZ-treated testis stained with anti- $\gamma H 2 A X$ (red) and anti-SYCP3 (green) antibodies. In control mice, the majority of meiotic cells have $\mathrm{HH} 2 \mathrm{AX}$ marks at the sex bodies only. In ATZ-treated mice, the majority of meiotic cells have $\mathrm{YH} 2 \mathrm{AX}$ marks at many chromosomes

To further examine synapsing efficiency in ATZ-treated mice, we stained chromosomes with an antibody against ATR (ataxia telangiectasia and Rad3-related), a marker of asynapsed chromosomes and silenced chromatin [97] (Fig. 3b). ATR acts stage-specifically to regulate multiple aspects of mammalian meiotic silencing [75]. If asynapsis persists at the pachytene stage, ATR leads to the induction of repressive post-translational modifications and irreversible gene silencing over many megabases [75]. To analyze the role of ATR in ATZ-treated mice, we counted the number of cells that showed staining of ATR at the sex body only or that showed simultaneous ATR staining of both XY bivalents and autosomes. In ATZ-treated mice, there was 1.8 times more ATR staining of autosomes (Fig. 3c). Consistent with previous data on the role of ATR in chromatin silencing [75], our experiments showed that ATZ treatment increases the number of chromosomes with incomplete synapsing.

\section{Delayed meiotic progression and increased apoptosis in} young prepubertal animals

To analyze the effect of the ATZ on meiotic progression during the first wave of spermatogenesis, we treated 

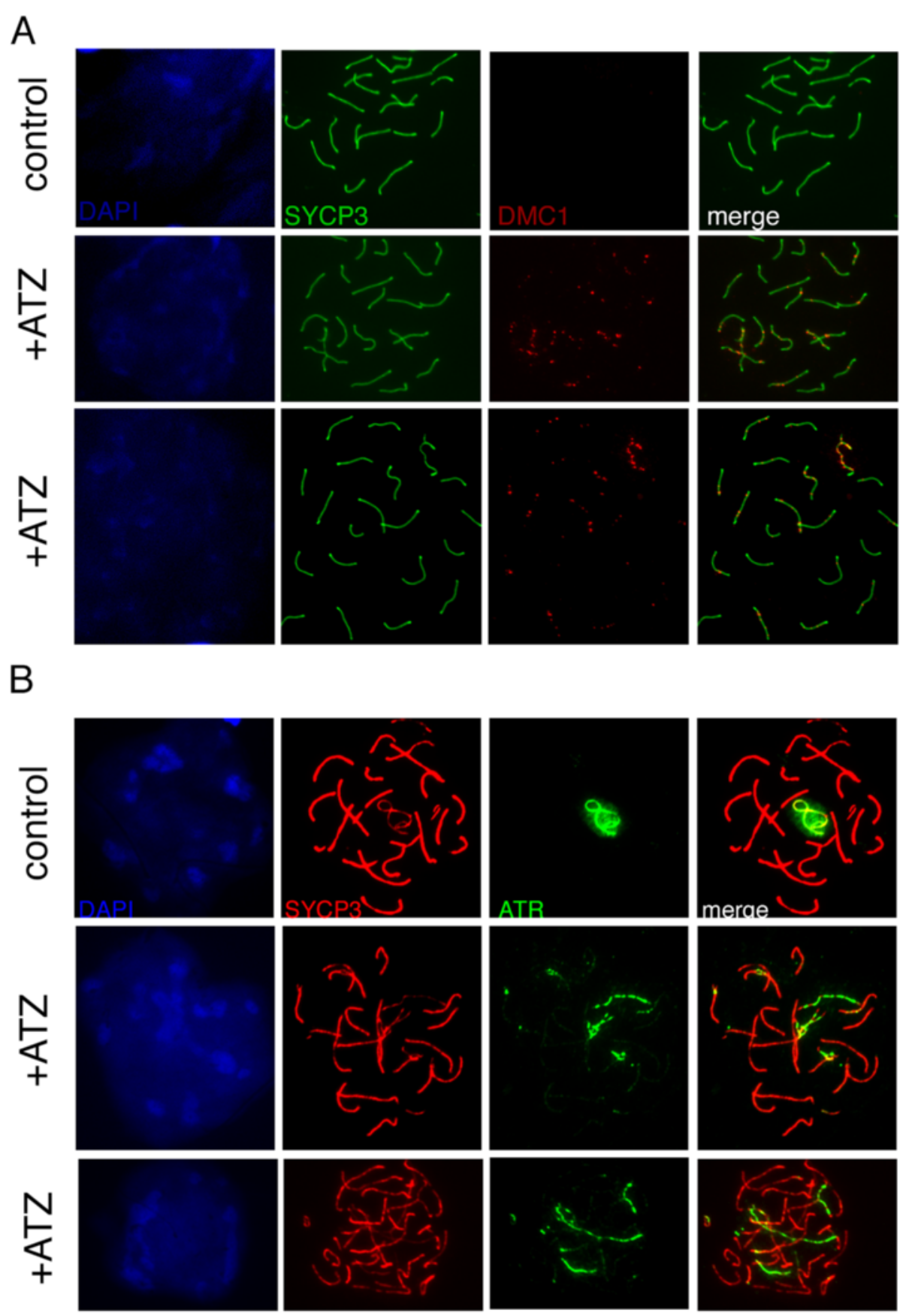

C control +ATZ

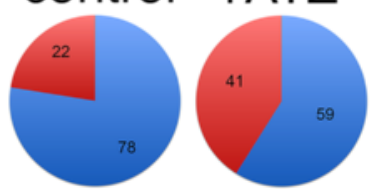

ATR staining only at sex chromosomes

ATR staining at sex chromosomes and autosomes

Fig. 3 (See legend on next page.) 
(See figure on previous page.)

Fig. 3 The proportions of DMC1- and ATR-positive cells increase upon treatment. a Spreads from control and ATZ-treated mice were stained with anti-DMC1 (red) and anti-SYCP3 (green). In control mice, the DSBs are repaired at this stage, such that no DMC1 foci are detectable. In ATZ-treated samples (middle and low panels), several DMC1 foci are detectable at the pachytene stage. b Spreads stained with anti-ATR (green) and anti-SYCP3 (red). In control mice, the ATR signal is detected in sex bodies only, while ATR staining is detected at several chromosomes in ATZ-treated mice. c Quantitative analysis of ATR staining. The spreads were costained with ATR and SYCP3 antibodies and classified according to pattern: sex body only (shown in blue) and sex body with staining of autosomal chromosomes (shown in red)

newborn males with ATZ. Young prepubertal animals have a higher proportion of cells at any given meiotic stage because the first wave of spermatogenesis is generally synchronous. The analysis of the testicular sections of treated animals revealed that the number of diplotene cells decreased 2.75 times compared to untreated animals, while the numbers of early pachytene and zygotene cells increased 1.9 times (Fig. $4 \mathrm{a}-\mathrm{c}$ ). These data are consistent with the results obtained from treated adult mice showing that ATZ has a profound effect on meiosis. As the first wave of spermatogenesis involves germ-cell apoptosis to regulate the number of germ cells under normal conditions [74], we assayed this process following ATZ treatment. ATZ treatment of young mice increased the number of apoptotic cells (Fig. 4d) compared to controls. The increased apoptosis rate in young mice is the result of an elevated number of germ cells with meiotic defects, which are eliminated during the first wave of spermatogenesis. Thus, ATZ exposure of young prepubertal mice causes a delay in meiosis similar to that observed in adult males.

\section{ATZ treatment affects the expression of genes involved in mitochondrial function, steroid-hormone function and GTPase activity}

To assess how ATZ affects spermatogenesis at the molecular level, we performed a comparative analysis of gene expression using Gene-Chip analysis. Using a fold-change cutoff value of 1.5 and a $p$-value cutoff of $<0.05$, we identified 51 genes that were differentially expressed between ATZ-treated and control mice (Additional file 1: Figure S5). The cellular heterogeneity of seminiferous tubules limits the sensitivity of this approach, as patterns of gene expression may vary by cell type. We confirmed differential expression by qPCR (Fig. 5a). Some differentially expressed genes (Tbx18, Fry1, Rrn3) were transcription factors, and their roles in spermatogenesis have not yet been elucidated. The expression of oxidative phosphorylation-related genes was increased (Nd6, Cox18, Dhrs1). These genes might be activated due to oxidative stress. Oxidative stress is the result of increased production of oxidizing species [11] caused by the metabolism of ATZ [80]. We confirmed that oxidative phosphorylation gene expression was associated
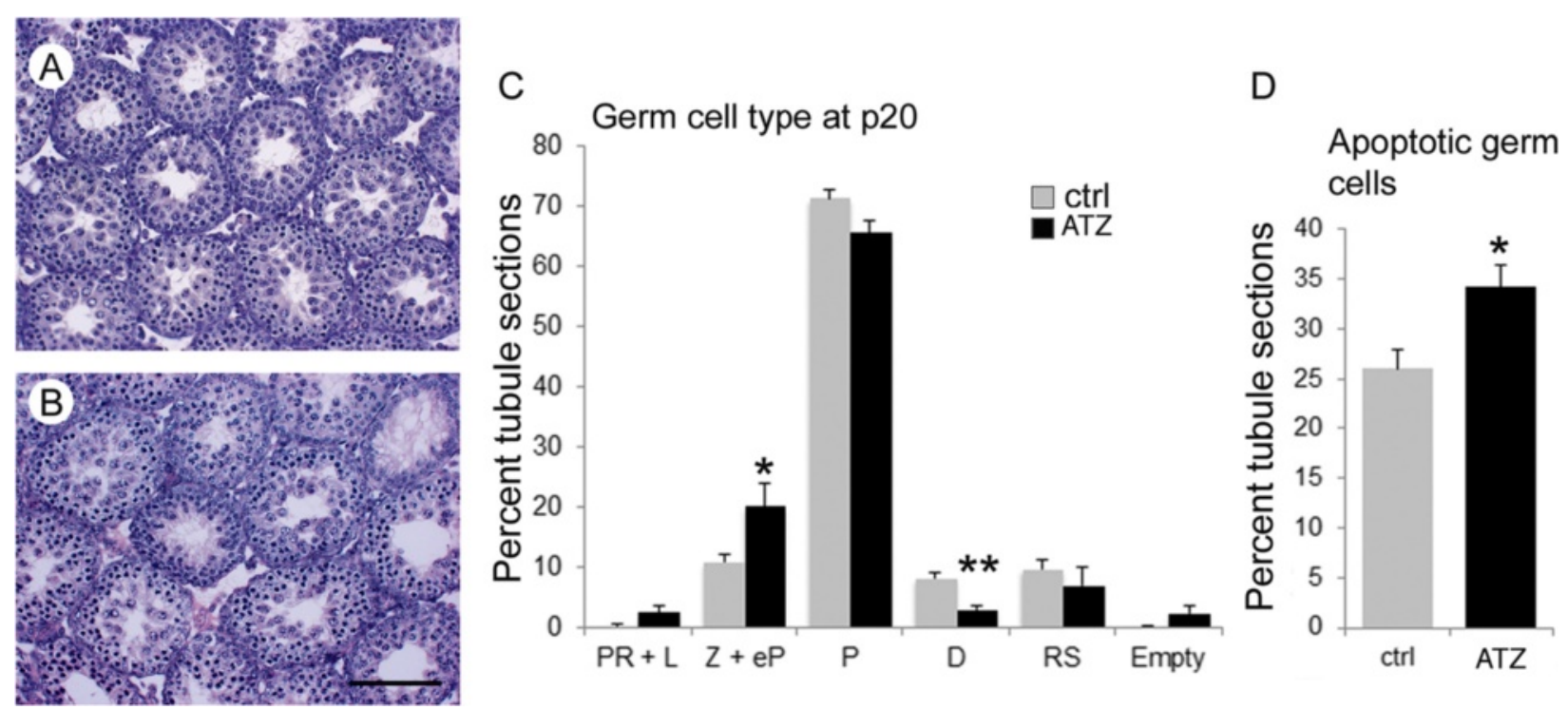

Fig. 4 Atrazine delays meiosis in prepubertal mice. H\&E straining of histological sections of a control and (b) ATZ-treated mice. The ATZ-treated mice have reduced numbers of cells in the seminiferous tubules. $\mathbf{c}$ The percentages of seminiferous tubule cross-sections in which preleptotene and leptotene $(P R+L)$ cells, zygotene and early pachytene $(Z+e P)$ cells, pachytene $(P)$ cells, diplotene $\mathbf{d}$ spermatocytes and round spermatids $(R S)$ represent the most advanced types of germ cells in control (grey bars) and ATZ-treated (black bars) testes at postnatal day 20. The percentage of empty tubules is also indicated. $\mathbf{d}$ TUNEL assays on testis histological sections from 20-day-old control and ATZ-treated mice. The results are presented as a percent of tubules containing apoptotic cells, and the data of at least five mice are plotted 


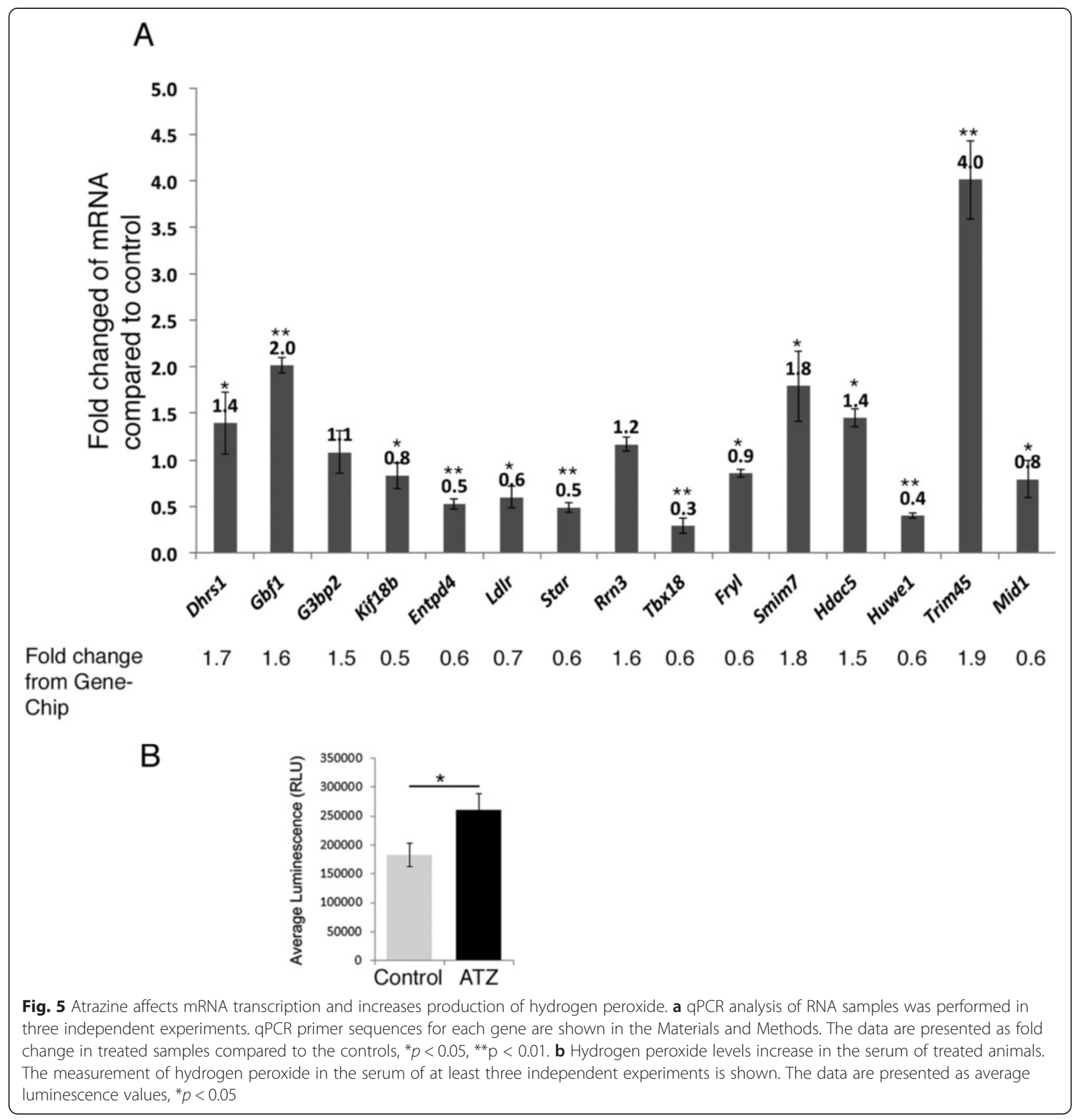

with increased ROS by measuring hydrogen peroxide in the serum (Fig. 5b).

The transport of cholesterol across the mitochondrial membrane is a key rate-limiting step in the regulation of steroid-hormone biosynthesis [70, 71, 84]. We found decreased levels of mRNAs encoding Star, a major protein responsible for cholesterol transport. The level of $L d l r$ (low-density lipoprotein receptor) also decreased, which affects cholesterol metabolism [35]. Other target genes included small GTPase regulatory proteins, such as G3bp2,
Nmt1, Sar1a (Ras GTPase signaling), Xpo7 (Ran GTPase, RNA export), Gbf1, and Arfgef1 (Arf GTPase protein trafficking). ARF1 GTPase is also required for the maintenance of mitochondrial functionality and dynamics [3].

We performed the analysis by using fold change cut-off value $\geq 2$. The short list includes 9 differentially expressed genes (Entpd4, Kif18b, 9230104L09Rik, ND6, Acsm2, Speer7-ps1, Speer4e, Xpo7, Gm17019) (Additional file 1: Table S1). These are genes, which play role in antioxidative stress response (ND6), xenobiotic metabolism 


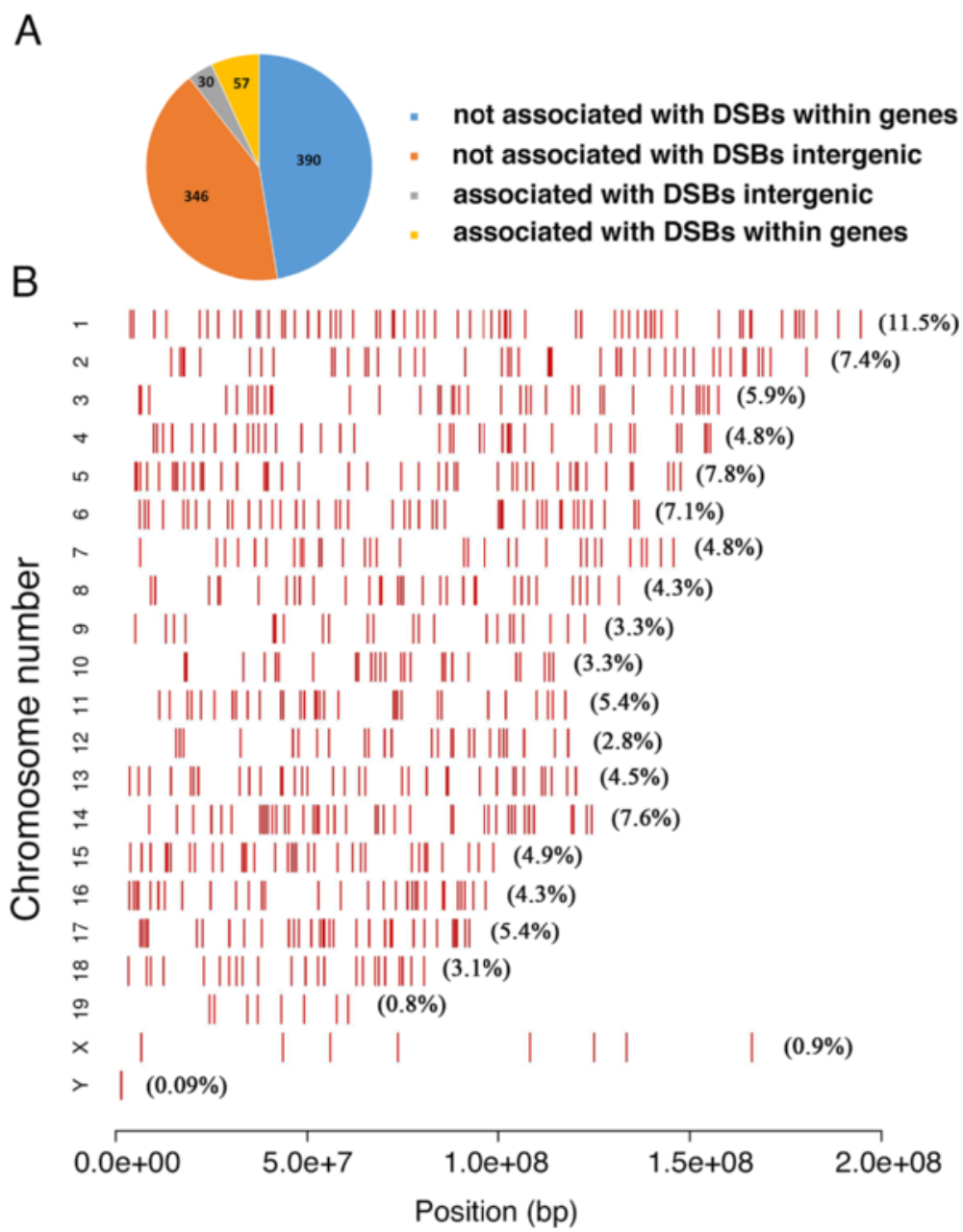

Fig. 6 Atrazine globally affects the distributions of H3K4me3 peaks. a The distribution of differential H3K4me3 peaks within genic and intergenic regions. The differential peaks were identified as described in the Material and Methods section; the genic regions are sequences located within genes (sequence within gene $+/-1 \mathrm{~kb}$ ), while the intergenic regions are places that do not overlap the genic regions. The majority of differential peaks are located in the genic regions. b The genome-wide distribution of differential H3K4me3 peaks in treated samples: the X-axis shows the chromosome coordinates; the Y-axis shows the chromosome number, and the red bars show the positions of the differential peaks on the chromosomes. The number of peaks per chromosome correlates with chromosome length; the longest, chromosome 1, has the greatest number of differential peaks (numbers in brackets indicate the percent of differential peaks located within a chromosome)

(Acsm2), cell division (Kif18b), and cell death (Entpd4) pathways.

Gene-ChiP analysis revealed that ATZ treatment affects many cellular processes, including steroid-hormone metabolism, oxidative phosphorylation and xenobiotic metabolism.

\section{Genome-wide sequencing reveals global changes in H3K4me3 marks following ATZ treatment}

H3K4me3 is a pivotal mark of active chromatin because it acts as a platform for the binding of multiple histone acetyltransferases, histone demethylases and nucleosomeremodeling complexes [44, 100]. As H3K4me3 marks are essential for meiosis, we asked whether treatment with ATZ affects these marks. To this end, we analyzed the genome-wide distribution of H3K4me3 marks in testis tissue. We found that 823 peaks were changed (Fig. 6a and Additional file 1: Files S1 and S2); of these, 799 peaks were increased in ATZ-treated mice, and only 24 were reduced. We confirmed the randomly chosen differential peaks by ChIP-QPCR (Additional file 1: Figure S6) (see Materials and Methods for details).

Among the differential H3K4me3 marks, 447 were located within coding genes (within gene $+/-1 \mathrm{~kb}$ ); this comprised only $54 \%$ of total altered peaks, almost half of which were located in intergenic regions (Fig. 6a). $25.3 \%$ of differential peaks are located within TSSs. Large numbers of peaks were located far from transcription start sites, suggesting that distally located elements, such as enhancers and ncRNA, are affected and may contribute to 
gene regulation. We compared the differential peaks to known ncRNA maps and found 180 peaks overlapping ncRNA (Additional file 1: File S3). The functions of most ncRNAs have yet to be elucidated.

Because endocrine function is affected in ATZ-treated animals, we asked whether H3K4me3 peaks changed in the vicinity of steroidogenesis genes or genes regulating steroid-hormone function. Both increased and decreased numbers of H3K4me3 sites were found in different parts of the Ncoa2 gene (responsible for steroid-dependent gene activation): H3K4me3 marks were reduced at exon 2 and increased near the TSS region in treated animals (Fig. 7a); expression of the latter gene was downregulated. We found increased H3K4me3 marks in Cyp19a1, also known as aromatase (Fig. 7b). The number of H3K4m3 marks was also decreased within the Star gene (Fig. 7c), a finding in agreement with the microarray data (Additional file 1: Figure S5). Because STAR activity is essential for steroid-hormone biosynthesis, decreased H3K4me3 marks and Star transcription suggest that the function of STAR in steroid-hormone metabolism is modified in ATZ-treated animals.

Subsequently, we asked whether differential H3K4me3 regions were located near genes that share common biological functions. We chose the subset of differential peaks within $+/-1 \mathrm{~kb}$ genes and performed functional annotation using DAVID software (details and parameters of analysis in Material and Methods section). We identified seven significantly enriched Gene Ontology (GO) clusters (Table 1).

The most significant GO cluster contained GTPase regulatory activity genes. Most of these genes are related to small Ras GTPase and Arf GTPase signal transduction regulators. Arf1 is required for vesicle transport [64] and mitochondrial homoeostasis [3]. Other enriched clusters include protein transport, maintenance of protein localization, cell junctions, and metal-ion binding (Table 1, clusters 1-6). Enriched cluster 7 contains genes regulating apoptosis and the DNA-damage response. We performed functional annotation of genes located upstream and downstream of ncRNA (Additional file 1: Table S3). We found that differential peaks overlapping ncRNA were surrounded by genes encoding proteins involved in adherens junctions and phagocytosis. Sertoli cells are responsible for the phagocytic elimination of apoptotic spermatogenic cells during normal and pathological conditions [58] suggesting that ATZ may increase the function of phagocytosis.

By using fold change cut-off value $\geq 2$ we found that 45 genomic loci have differential H3K4me3 marks (Additional file 1: Table S2). 7 peaks are located within TSS of some genes (Speer4d, Dynlt1b, Trim45, Plcb4, Loxl2, Ank3), 38 peaks are far from TSS of any genes, suggesting the marks at distally located promoters, enhancers and non-coding RNAs are deregulated. The differential peaks are located within genomic regions nearby genes of spermatogenesis function (Speer family, Synb, Ncoa2, Pabpc1, Ropn1, Dhh); cell adhesion and motility (Ank3, Pcdhb3, Dynlt1b, Syt17, Stxbp6); transcription regulation and signaling (Trim45, Vgll3, Hhat, Plcb4, Nps, Hgf); oxidoreductase (Loxl2, Cyp4f18), cell cycle and cell death (Nedd1, Sgol2b, Entpd4). The analysis confirms that ATZ damage spermatogenesis function most likely due to metabolism of ATZ.

Our data show that ATZ changes the number of H3K4me3 marks in genes with a wide range of important cellular functions.

\section{Comparison of ChIP-Seq and Gene-Chip data reveal common genes related to GTPase regulation, mitochondrial function and steroid-hormone levels}

ChIP-seq and Gene-Chip have different sensitivities. The ChIP-Seq method is very sensitive; it involves integrating a large number of short sequencing reads. Compared to RNA sequencing, the Gene-ChiP assay is less sensitive in detecting genes with very low expression and is less accurate in detecting highly expressed genes [107]. To compare the two datasets, we calculated the averaged signal values of ChIP-Seq peaks at the TSS of differentially expressed genes. We found that 31 genes were present (Table 2) in both datasets, while six differential genes identified by Gene-Chip had no H3K4me3 peaks either because they were encoded by mitochondrial DNA or because no peaks were identified near the TSS. All differentially expressed GTPase-regulating genes had altered H3K4me3 marks, suggesting that the transcription of genes was mediated via epigenetic modifications of histones. However, 13 differential genes had no changes in H3K4me3 marks at their TSS; the expression of mRNA from these genes could be modulated by other mechanisms, such as distally located enhancers, epigenetic mechanisms and ncRNA. Thus, atrazine induces epigenetic modifications at the TSS of the majority of differentially expressed genes.

\section{Regions showing altered epigenetic marks are enriched at the Nr5a2-binding site}

To address whether regulatory DNA motifs are present within regions containing altered epigenetic marks, we used MEME-ChIP [49], which is designed to discover motifs in large sets of DNA sequences. We analyzed the summits of 100-bp sequences within differential peaks. Parameters and details are described in the Materials and Methods. We found a significantly enriched motif among the differential peaks. We compared this motif with known motifs using TomTom [93] and found that part of the discovered motif sequence was significantly similar to the Nr5a2-binding site (Fig. 8). Recent work showed that ATZ activates NR5A receptors via phosphorylation and increases cAMP production and PI3K 
A

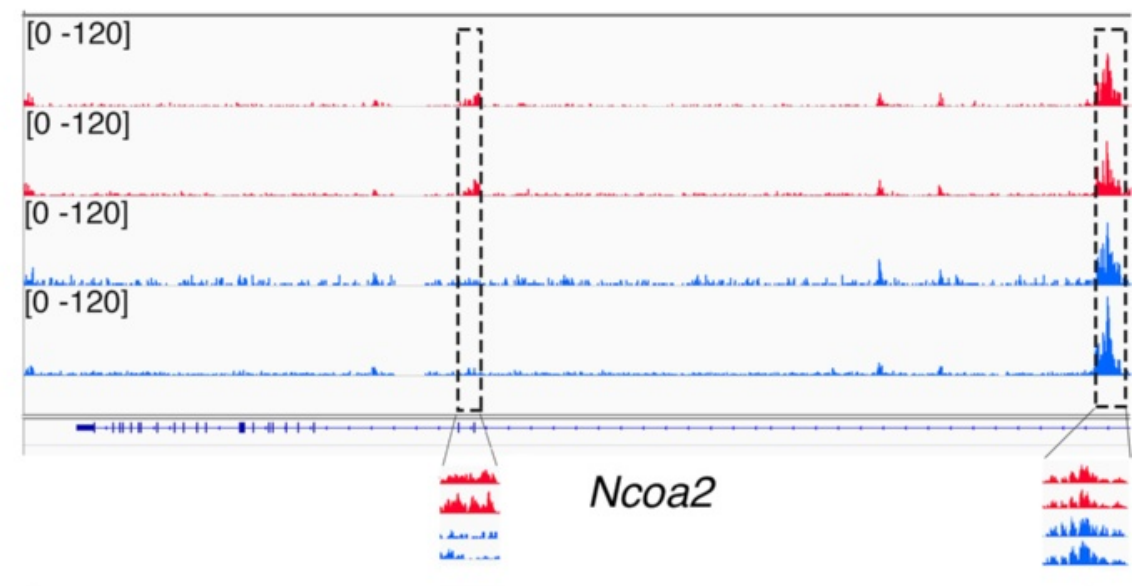

B
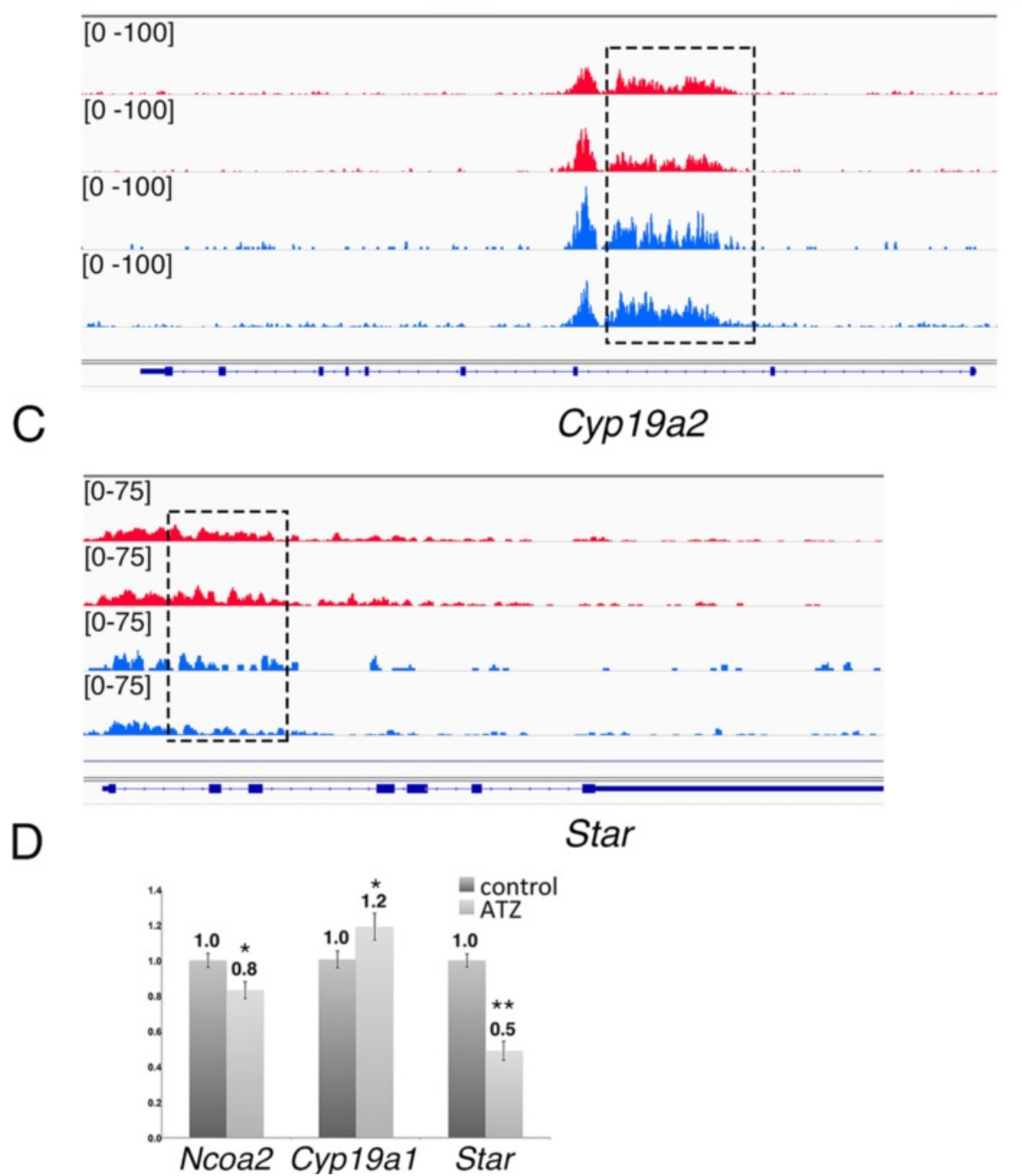

Fig. 7 (See legend on next page.) 
(See figure on previous page.)

Fig. 7 ATZ affects the number of H3K4me3 marks and mRNA levels of genes involved in androgen signaling and testosterone metabolism. a The differential H3K4me3 peaks in the Ncoa2 gene (there are two regions with changes in H3K4me3 marks outlined in boxes), b Cyp19a1 gene and $\mathbf{c}$ Star gene. The Y-axis presents the plotted values of tags at each position after normalizing to all reads in the same dataset (intensity range shown on the left side of the plot); the $X$-axis shows the schema of the gene; rectangles are exons, and lines are introns. Note that the differential regions are located within genes. The H3K4me3 profiles from control biological replicates are shown in red, and those from ATZ-treated mice are in blue. For illustration, the "Integrative Genomic Viewer" (IGV) software version 2.3 .36 was used. $\mathbf{d}$ qPCR analysis of the Ncoa2, Cyp19a1, and Star genes. qPCR analysis of RNA samples was performed in three independent experiments. Primer sequences for each gene are shown in the Materials and Methods section. The data are presented as fold change in treated samples compared to controls, ${ }^{*} p<0.05,{ }^{* *} p<0.01$

signaling [91]. To further understand the involvement of NR5A2 in the transcriptional regulation of ATZ-treated mice, we performed a functional annotation of genes located near presumed Nr5a2-binding sites in ATZtreated mice. We found enrichment of genes with enzyme inhibitor activity (Cst13, Cst8, Cst9, Spock3) and genes encoding proteins involved in the immune response (Ptprc, Cd55, Daf2), locomotory behavior (Nrp2, Ccl21c, Ccl21b, Gm1987, Klhl1) and lipoprotein metabolism (Apol10a, Apol9a, Apol7b) (see also Additional file 1: Table S4).

Our data show that Nr5a2-binding sites are significantly enriched in differential peaks in ATZ-treated testes tissue, suggesting an important role for NR5A2 in the transcriptional network of ATZ- treated mice.

\section{ChIP-Seq reveals deregulation of $\mathrm{H} 3 \mathrm{~K} 4 \mathrm{me} 3$ marks associated with DSBs}

We compared the altered distribution of H3K4me3 peaks observed in our study to a published DSB-hotspot maps of the C57BL/6 J mouse strain [12, 86]. H3K4me3 marks within 87 regions were elevated in genomic regions overlapping DSB hotspots (Fig. 6a). Fifty-seven of these H3K4me3 peaks were located within genes. Most of the differential H3K4me3 peaks were associated with the strongest DSB hotspots (Fig. 9a).

It is remarkable that $\mathrm{H} 3 \mathrm{~K} 4 \mathrm{me} 3$ marks at the PAR region of $\mathrm{X}$ chromosomes were decreased in ATZ-treated mice (Fig. 9b). This region of PAR contains a CpG island with 127 CpGs.

Interesting, altered $\mathrm{H} 3 \mathrm{~K} 4 \mathrm{me} 3$ peaks associated with DSBs were located within very large mouse genes (Table 3). Erbb4 and Nrxn1 are known to contain common fragile sites (CFS) [88], which are regions of profound genomic instability [45]. Many breakpoints are enriched in AT stretches, which affect replication efficiency by forming secondary structures that stall progression of the replication fork [106]. We examined the AT content in genes and found increased AT content and AT stretches (Table 3).

Our data show that ATZ treatment affects H3K4me3 marks at genomic regions overlapping DSBs regions, including PAR and very large genes.

\section{Discussion}

The objective of this study was to investigate the effects of ATZ in meiosis, which is essential for the production of normal gametes. We used atrazine for our study because it is widely distributed; it is the most common pollutant in the environment and is still in use in many countries. Mice were treated with doses lower than those used in many other studies but exceeding the authorized limits. We chose this dose to determine whether it can alter molecular events underlying gametogenesis, although it does not trigger apoptosis or cause obvious changes in testicular morphology. We treated mice for three weeks to cover the period from entry into meiosis until the diplotene stage of prophase I. Specifically, we analyzed meiotic progression, RNA expression and the distribution of genome-wide histone H3K4me3 marks.

\section{The effects of ATZ on mitochondria and steroid-hormone metabolism}

One of the reasons why ATZ is toxic to the testis is its effect on mitochondrial function. Our data suggest that the testicular cells of exposed mice suffer from impaired mitochondrial function, a result consistent with the findings of previous studies $[43,55,82,94]$. Rats chronically exposed to ATZ have swollen mitochondria with disrupted cristae [47]. Many studies have demonstrated that the oxidative stress induced by atrazine causes increased activity of the antioxidant enzymes superoxide dismutase, catalase, glutathione peroxidase, and glutathione-s-transferase, increasing the production of $\operatorname{ROS}[2,39,85]$.

We found that exposure of mice to a relatively low dose of ATZ led to diminished testosterone levels. Decreased testosterone can be explained by impaired cholesterol metabolism and increased activity of aromatase CYP19A1, which converts testosterone to estradiol. We found an increase in the level of Cyp19a1 mRNA and increased numbers of $\mathrm{H} 3 \mathrm{~K} 4 \mathrm{me} 3$ marks in this gene. The increase in CYP19A1 activity after ATZ exposure has been demonstrated in many studies [22, 31, 77, 91]. It was suggested that ATZ activates CYP19A1 via NR5A-receptor binding [23]. There are Nr5a1-binding sites in the Cyp19a1 promoter. However, Pezzi et al. proposed that NR5A2 plays an important role in the regulation of Cyp19a1 expression in Leydig cells [66]. We also found a putative binding site 
Table 1 The Gene Ontology (GO) clusters identified by DAVID

\begin{tabular}{|c|c|c|c|}
\hline Cluster 1 & Enrichment Score: 3.18 & Count & $P$ P_Value \\
\hline GO:0030695 & GTPase regulator activity & 16 & 1.10E-04 \\
\hline GO:0060589 & nucleoside-triphosphatase regulator activity & 16 & 1.30E-04 \\
\hline GO:0051056 & regulation of small GTPase mediated signal transduction & 12 & 1.90E-04 \\
\hline GO:0005085 & guanyl-nucleotide exchange factor activity & 9 & 8.40E-04 \\
\hline GO:0046578 & regulation of Ras protein signal transduction & 9 & $2.50 \mathrm{E}-03$ \\
\hline GO:0005096 & GTPase activator activity & 8 & $1.50 \mathrm{E}-02$ \\
\hline Cluster 2 & Enrichment Score: 2.23 & Count & P_Value \\
\hline GO:0008104 & protein localization & 21 & 1.80E-03 \\
\hline GO:0015031 & protein transport & 17 & 1.00E-02 \\
\hline GO:0045184 & establishment of protein localization & 17 & 1.10E-02 \\
\hline Cluster 3 & Enrichment Score: 2.02 & Count & P_Value \\
\hline GO:0005856 & cytoskeleton & 28 & $3.70 \mathrm{E}-03$ \\
\hline GO:0043232 & intracellular non-membrane-bounded organelle & 39 & $1.50 \mathrm{E}-02$ \\
\hline GO:0043228 & non-membrane-bounded organelle & 39 & $1.50 \mathrm{E}-02$ \\
\hline Cluster 4 & Enrichment Score: 1.81 & Count & P_Value \\
\hline GO:0045185 & maintenance of protein location & 4 & $5.50 \mathrm{E}-03$ \\
\hline GO:0051235 & maintenance of location & 4 & 8.80E-03 \\
\hline GO:0032507 & maintenance of protein location in cell & 3 & $3.00 \mathrm{E}-02$ \\
\hline GO:0051651 & maintenance of location in cell & 3 & 4.10E-02 \\
\hline Cluster 5 & Enrichment Score: 1.71 & Count & P_Value \\
\hline GO:0015629 & actin cytoskeleton & 9 & $8.20 \mathrm{E}-03$ \\
\hline GO:0030054 & cell junction & 14 & 1.50E-02 \\
\hline GO:0005912 & adherens junction & 6 & 1.70E-02 \\
\hline GO:0070161 & anchoring junction & 6 & 2.90E-02 \\
\hline GO:0016323 & basolateral plasma membrane & 6 & 4.80E-02 \\
\hline Cluster 6 & Enrichment Score: 1.62 & Count & P_Value \\
\hline GO:0043167 & ion binding & 67 & $2.10 \mathrm{E}-02$ \\
\hline GO:0043169 & cation binding & 66 & 2.40E-02 \\
\hline GO:0046872 & metal ion binding & 65 & $2.80 \mathrm{E}-02$ \\
\hline Cluster 7 & Enrichment Score: 1.52 & Count & P_Value \\
\hline GO:0006508 & proteolysis & 24 & 7.50E-03 \\
\hline GO:0019941 & modification-dependent protein catabolic process & 13 & 3.30E-02 \\
\hline GO:0043632 & modification-dependent macromolecule catabolic process & 13 & 3.30E-02 \\
\hline GO:0009057 & macromolecule catabolic process & 15 & 4.50E-02 \\
\hline GO:0051603 & proteolysis involved in cellular protein catabolic process & 13 & 4.50E-02 \\
\hline GO:0044257 & cellular protein catabolic process & 13 & 4.70E-02 \\
\hline
\end{tabular}

for NR5A2 within altered H3K4me3 peaks in Cyp19a1. Our data support the hypothesis that NR5A2 plays an essential role in activating CYP19A1. It has been suggested that the stimulatory effects of ATZ on the NR5A receptor subfamily (Nr5a1 and Nr5a2) are mediated by receptor phosphorylation, amplification of cAMP and PI3K signaling [91]. These authors proposed that hormone networks are altered in many species exposed to ATZ via the convergence of NR5A activity and cAMP signaling [91]. We found enrichment of several putative NR5A sites near genes encoding proteins involved in the immune response and lipoprotein metabolism. Recent work has shown that the silencing of $N r 5 a 2$ in colon cancer cell lines affects signal transduction, GTPase activity, cholesterol transport, and apolipoprotein expression [9]. We propose that NR5A2 regulates a number of cellular 
Table 2 The Gene-Chip and ChIP-seq agreement

\begin{tabular}{|c|c|c|c|c|}
\hline Affymetrix ID & Official gene name & FC Gene Chip & FC Chip-Seq & Official gene symbol, full description \\
\hline 17550548 & Acsm2 & 2.1 & 1.2 & Acyl-coa synthetase medium-chain family member 2 \\
\hline 17205319 & $\operatorname{Cox} 18$ & 1.8 & 1.1 & cytochrome c oxidase assembly protein 18 \\
\hline 17200441 & Dhrs 1 & 1.7 & 1.1 & Dehydrogenase/reductase (SDR family) member 1 \\
\hline 17205257 & Gbf1 & 1.6 & 1.2 & Golgi-specific brefeldin A-resistance factor 1 \\
\hline 17202563 & MrpL27 & 1.5 & 1.2 & Mitochondrial ribosomal protein L27 \\
\hline 17205437 & Arfgef1 & 1.6 & 1.2 & ADP-ribosylation factor guanine nucleotide-exchange factor 1 \\
\hline 17201149 & Xpo7 & 1.5 & 1.4 & Exportin 7; similar to Ran-binding protein 16 \\
\hline 17308165 & Entpd4 & 0.4 & 0.6 & Ectonucleoside triphosphate diphosphohydrolase 4 \\
\hline 17449641 & G3bp2 & 1.5 & 1.2 & Gtpase activating protein (SH3 domain) binding protein 2 \\
\hline 17308149 & Gm16677 & 0.6 & 0.6 & Predicted gene 16677 \\
\hline 17548436 & Gm17019 & 2.1 & 3.7 & Predicted gene 17019 \\
\hline 17203369 & Sarla & 1.6 & 1.1 & SAR1 gene homolog A (S. Cerevisiae) \\
\hline 17515315 & Ldlr & 0.7 & 0.8 & Low density lipoprotein receptor \\
\hline 17500195 & Star & 0.6 & 0.7 & Steroidogenic acute regulatory protein \\
\hline 17201763 & Nmt1 & 1.6 & 1.1 & N-myristoyltransferase 1 \\
\hline 17203277 & Psmal & 1.5 & 1.1 & Proteasome (prosome, macropain) subunit, alpha type 1 \\
\hline 17453132 & Psph & 0.6 & 0.9 & Phosphoserine phosphatase \\
\hline 17323063 & $\operatorname{Rrn} 3$ & 1.6 & 1.1 & RRN3 RNA polymerase I transcription factor homolog (yeast) \\
\hline 17445634 & Gm9758 & 1.8 & 3.1 & Spermatogenesis associated glutamate (E)-rich protein $4 \mathrm{e}$ \\
\hline 17446524 & Speer4b & 1.6 & 1.4 & Spermatogenesis associated glutamate (E)-rich protein $4 \mathrm{~b}$ \\
\hline 17445689 & Speer4c & 1.5 & 1.5 & Spermatogenesis associated glutamate (E)-rich protein 4e \\
\hline 17445673 & Speer4e & 2 & 6 & Spermatogenesis associated glutamate (E)-rich protein $4 \mathrm{e}$ \\
\hline 17434884 & Speer7-ps1 & 2.1 & 6.2 & Spermatogenesis associated glutamate (E)-rich protein 7, pseudogene 1 \\
\hline 17434864 & Speer8-ps 1 & 1.8 & 2.4 & Spermatogenesis associated glutamate (E)-rich protein 8, pseudogene 1 \\
\hline 17529481 & Tbx 18 & 0.6 & 0.8 & T-box18 \\
\hline 17201539 & Kif18b & 1.6 & 1.1 & Kinesin family member $18 \mathrm{~B}$ \\
\hline 17401007 & Trim45 & 1.9 & 2.4 & Tripartite motif-containing 45 \\
\hline 17535269 & 1700020N15Rik & 0.6 & 1.2 & RIKEN cdna 1700020 N15 gene \\
\hline 17201329 & Ccdc103 & 0.6 & 1.2 & Coiled-coil domain containing 103 \\
\hline 17207313 & Cpsf7 & 0.7 & 1.2 & Cleavage and polyadenylation specific factor 7 \\
\hline 17201293 & Eftud2 & 0.6 & 1.2 & Elongation factor Tu GTP binding domain containing 2 \\
\hline 17206471 & Eif5 & 0.6 & 1.2 & Similar to Eukaryotic translation initiation factor 5 \\
\hline 17448749 & Fryl & 0.6 & 1.2 & Furry homolog-like (Drosophila) \\
\hline 17208347 & Hdac5 & 1.5 & 1 & Histone deacetylase 5 \\
\hline 17538773 & Huwel & 0.6 & 1 & HECT, UBA and WWE domain containing 1 \\
\hline 17546762 & Mid1 & 0.6 & 1.5 & Similar to midline 1 \\
\hline 17207105 & Pkd1 & 0.7 & 1 & Polycystic kidney disease 1 homolog \\
\hline 17202313 & Psap & 1.7 & 1 & Prosaposin \\
\hline 17204631 & Smim7 & 1.8 & 0.9 & Small integral membrane protein 7 \\
\hline 17438319 & Tmem165 & 0.6 & 1.1 & Transmembrane protein 165 \\
\hline 17392600 & 9230104L09Rik & 0.5 & ND & RIKEN cdna 9230104 L09 gene \\
\hline 17290163 & $\mathrm{Cc} 128$ & 1.6 & ND & Chemokine (C-C motif) ligand 28 \\
\hline 17413061 & Gm5859 & 0.5 & ND & Similar to 4933409K07Rik protein \\
\hline
\end{tabular}


Table 2 The Gene-Chip and ChIP-seq agreement (Continued)

\begin{tabular}{lllll}
\hline 17477347 & Klk1b22 & 1.8 & ND & Kallikrein 1-related peptidase b22 \\
17233226 & Lilrb4 & 0.6 & ND & Glycoprotein 49 A; leukocyte immunoglobulin-like receptor, subfamily B, member 4 \\
17532649 & Nd6 & 2.3 & ND & NADH dehydrogenase subunit 6 \\
\hline
\end{tabular}

pathways and promotes transcriptional network activation under pathological conditions.

\section{Effects of ATZ exposure on meiosis and recombination}

Specifically, we found increased numbers of cells in the early stages (zygotene and pachytene) of meiosis in ATZtreated mice. We also detected increased numbers of cells with DMC1 foci on the sex chromosomes. Chromatin at DSB sites contains a special environment near PRDM9binding motifs, which are nucleosome-depleted [6]. PRDM9-modified nucleosomes create an environment for DNA repair machinery [6]. We suggest that DSB hotspots serve as sensitive targets of DNA-damaging reagents because of their open chromatin structure and enrichment with repeated elements. We found an increase in H3K4me3 at DSB sites associated with strong hotspots, probably reflecting inefficient DSB repair at strong DSB hotspots or repression of HR. If recombination goes wrong way it will be suppressed by cellular mechanisms. Recently, it was found that the helicase Srs 2 in yeast [99], antirecombinase RTEL-1 in C. elegans [105], and human PARI [54] suppress inappropriate recombination, which is highly toxic to cells as a source of genomic rearrangements.

The disrupting effect of ATZ is most striking at the sex chromosomes. Recombination at sex chromosomes occurs at 40-Mb-long pseudoautosomal regions of X and Ychromosomes. Recombination at the PAR region differs significantly between sexes: in males, this region has the highest recombination rate [26]. PAR has a different chromatin structure; PAR DNA occupies unusually long chromosomal axes [42], which may play a role in accessibility to DNA damaging factors. DSB formation and repair at PAR is a limiting step in meiosis [42]. ATZ can modulate DSB machinery at PAR. The toxic effect of ATZ on sex chromosomes was previously shown in Drosophila, in which it significantly increased X-linked recessive lethality and $\mathrm{X}$ or $\mathrm{Y}$ loss after treatment by larval feeding [56]. It is also important that the H3K4me3 peak at PAR includes a CPG island, a region where DSB repair could be affected due to chromatin silencing and reduced access to DNA repair machinery [60].

Altered H3K4me3 peaks are associated with DSBs in large genes, such as Erbb4 and Nrxn1. Within human analogues of these genes, there are sites of breakage. Common fragile sites (CFS) are highly conserved between species, and these regions are often enriched in structural variants, including duplications and retrotransposon elements [45]. DNA damage at CFS arises due to exogenous factors, including UV and ionizing radiation, chemotherapy and reactive oxygen species [37]. Exposure to pesticides results in increased susceptibility of fragile sites to breakage in workers exposed to pesticides $[57,79]$.

It is possible that we failed to detect a set of DSBs not associated with recombination because a set of DSBs induced by ATZ is absent from published datasets. Future work will address this possibility.

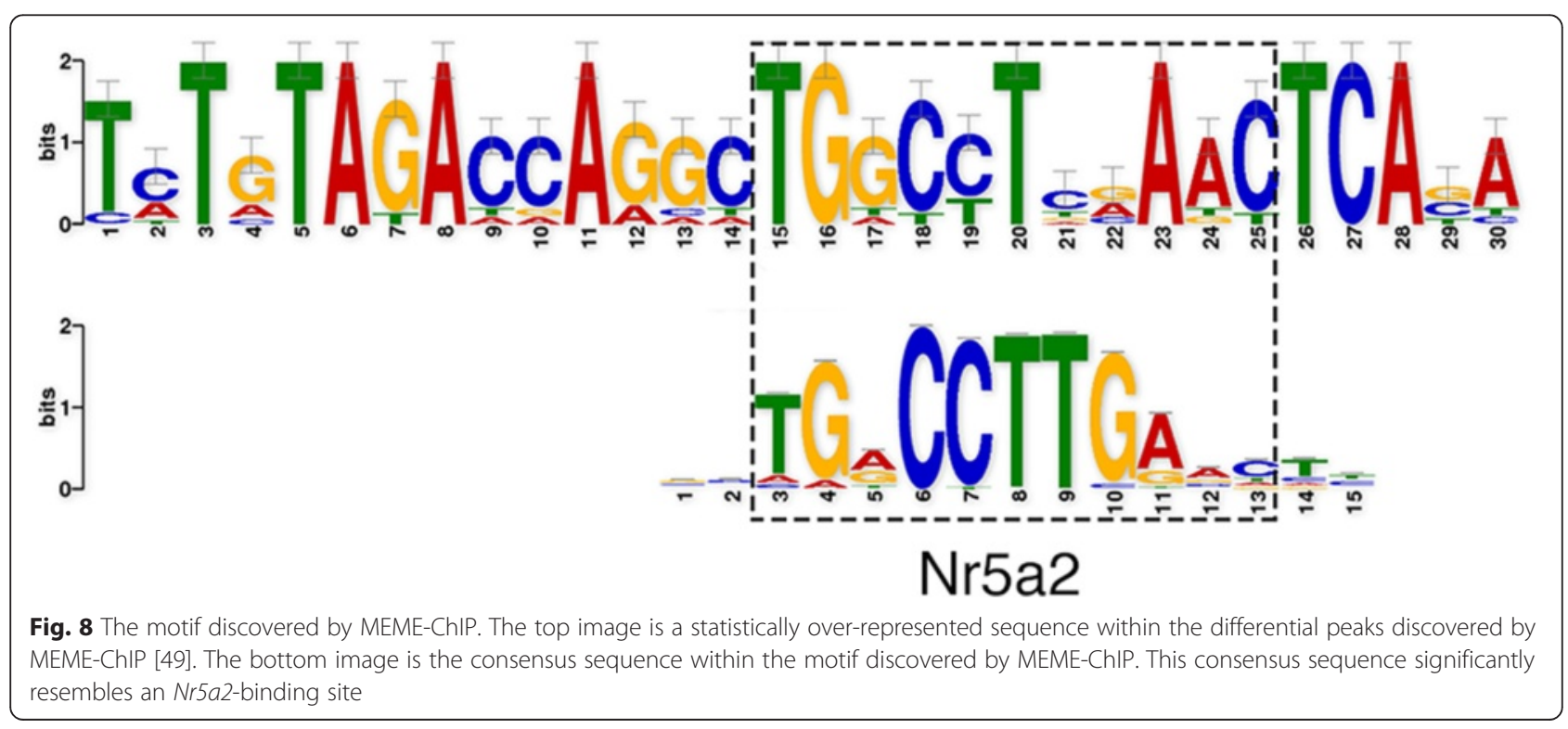




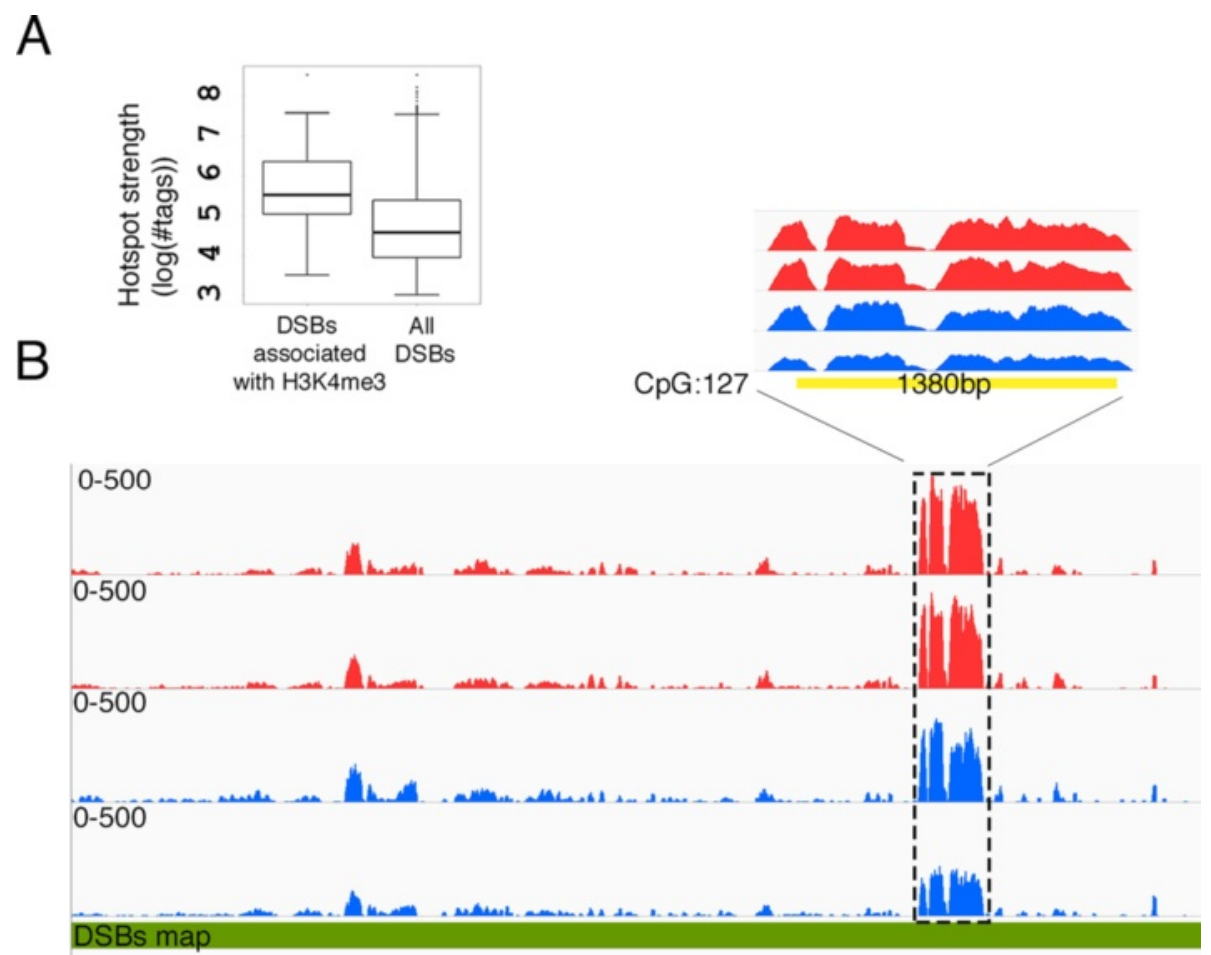

Fig. 9 Differential peaks are associated with DSB regions. a The association of differential H3K4me3 peaks with the hottest DSB hotspots. The DMC1 tags associated with differential H3K4me3 peaks were extracted from published datasets [12,86], and intensity values were calculated and presented as $\log$ (\#tags) on the left plot. The right plot is the intensity of all DSB hotspots signal from the whole dataset [86]. The median signal of DSB peaks associated with differential H3K4me3 peaks was higher than the median signal of all DSBs hotspots, suggesting that differential trimethylation peaks in ATZ-treated mice are associated with the strongest hotspots. $\mathbf{b}$ The PAR region in ATZ-treated mice has a decreased number of H3K4me3 marks. The DSB map was downloaded from GEO from a previously published work [86]. Plots from controls are in red, plots from treated samples are in blue, and the CpG island is shown in yellow

In summary, our data elucidates the molecular mechanisms underlying ATZ's negative effect on meiosis. Importantly, we found a number of effects at the molecular level at a stage in which no morphological changes are detectable.

\section{Conclusions}

In this study, we demonstrated that ATZ affects meiosis in adult and young prepubertal animals. ATZ affects recombination during meiosis and many cellular processes, leading to a decrease in the number of spermatozoa in mice. In addition, the technical approaches used in this research will facilitate the design of studies aimed at understanding the effects of environmental toxicants on reproduction.

\section{Methods}

Animals and atrazine exposure

All animal procedures were performed according to the guidelines for animal models in research defined by the Ethics Committee and approved by the Ministry of France (reference project number is 01861.02). All experiments were performed by A.G.P. or F.S, who

Table 3 The altered H3K4me3 peaks are overlapping with DSB sites in very large genes

\begin{tabular}{|c|c|c|c|c|c|}
\hline Gene & Length $(\mathrm{Mb})$ & Number of DSBs within gene & The highest DSB Signal value within genes & AT content & number of AT stretches \\
\hline Erbb4 & 1.1 & 6 & 15133 & $64 \%$ & 8 \\
\hline Nrxn1 & 1.1 & 10 & 2606 & $63 \%$ & 10 \\
\hline Hs6st3 & 0.7 & 14 & 2210 & $59 \%$ & 2 \\
\hline Cntnap5b & 0.7 & 5 & 2909 & $62 \%$ & 6 \\
\hline Hpse2 & 0.6 & 3 & 3502 & $60 \%$ & 0 \\
\hline Gmds & 0.5 & 5 & 1961 & $61 \%$ & 1 \\
\hline Denndla & 0.5 & 6 & 12226 & $58 \%$ & 0 \\
\hline
\end{tabular}


are qualified for laboratory animal care and use. The C57BL/6 J mouse strain was used. Five-week-old adult mice were treated for three weeks with atrazine at a concentration of $100 \mathrm{mg} / \mathrm{l}$ in drinking water. The amounts consumed were measured daily, with the ATZ uptake corresponding to nearly $25 \mathrm{mg} / \mathrm{kg} /$ days (average uptake $5 \mathrm{ml} /$ day). After three weeks of treatment followed by two weeks without treatment, mice were euthanized, and reproductive organs were dissected. At least five independent experiments were performed with at least six-to-ten animals in each group. Young prepubertal mice were treated from postnatal day 1 until day 20 by administering oil or atrazine suspended in oil to their mothers at a dose of $25 \mathrm{mg} / \mathrm{kg} /$ day with at least four animals in each group. The mice were euthanized, and the testes and epididymis were used for analysis.

\section{Testosterone and FSH quantification}

Serum was collected from ketamine/xylazine-anaesthetized adult animals by terminal cardiac exsanguination and aliquots were stored at $-20{ }^{\circ} \mathrm{C}$. Testosterone levels in the serum were assayed in duplicate using a commercial radioimmunoassay (RIA) based on competitive binding with I125-labeled testosterone (Immunotech, Beckman Coulter, Villepinte, France), according to the manufacturer's recommendations. FSH measurements were conducted according a standard protocol provided by a FSH measurement kit (KA2330, Abnova, Walnut CA, USA). In each hormone measurement, the data from at least 10 treated and control animals were averaged and plotted, and the results were expressed in nanograms per milliliter.

\section{Analysis of histology, apoptosis and numbers of germ cells/Sertoli cells}

For the histological analysis, testis samples were fixed in Bouin's solution and embedded in paraffin. Histological sections $(5-\mu \mathrm{m}$ thick) were stained with hematoxylin and eosin (H\&E). The percentage of affected seminiferous tubules was established by counting the H\&E-stained crosssections of seminiferous tubules from the testes of at least three animals. The staging of cells in seminiferous tubes was performed according to an established method [76], with analysis of at least 600 tubule sections. For immunohistochemistry (IHC), the animals were perfused, and the testes were fixed for $24 \mathrm{~h}$ in $4 \%$ (wt/vol) paraformaldehyde (PFA) and then embedded in paraffin. For the detection of apoptotic cells, TUNEL assays were performed using the In Situ Cell-Death, Fluorescein (Roche Diagnostics, France). For IHC, $5-\mu$ m-thick testis sections were incubated overnight at $4{ }^{\circ} \mathrm{C}$ with goat anti-PLZF diluted at 1:500 and rat anti-GATA1 diluted at 1:50. The sections were all counterstained with $0.001 \%$ ( $\mathrm{vol} / \mathrm{vol}$ ) 4,6- diamidino-2-phenylindole dihydrochloride (DAPI) and mounted in Vectashield (Vector Laboratories, UK).

\section{Hydrogen peroxide measurement}

Measurement of hydrogen peroxide was carried out with the ROS-Glo ${ }^{\mathrm{TM}} \mathrm{H}_{2} \mathrm{O}_{2}$ Assay kit (Promega, Madison, WI), according to the manufacturer's instructions. Briefly, $80 \mu \mathrm{l}$ of serum from adult control and ATZ-treated mice were mixed with $20 \mu \mathrm{l}$ of $\mathrm{H}_{2} \mathrm{O}_{2}$ substrate and held for $6 \mathrm{~h}$ at $37^{\circ} \mathrm{C}$. Then, $100 \mu$ l of ROS-Glo ${ }^{\text {TM }}$ detection solution was added and incubated for $20 \mathrm{~min}$ at room temperature, and relative luminescence was measured in a plate reader.

\section{Cells sorting by flow cytometry}

Germ cells were isolated from control and ATZ-treated testis tissue. The testis cells were subjected to collagenase and DNAse treatment and purified by FACS, as described previously [73]. The dispersed cells were fixed in $1 \%$ (wt/ vol) buffered PFA for $20 \mathrm{~min}$ at $4{ }^{\circ} \mathrm{C}$ and permeabilized in a solution of $0.2 \%$ (wt $/ \mathrm{vol}$ ) saponin containing propidium iodide to label the DNA. The cells were sorted at concentration of $1 \times 10^{6}$ cells $/ \mathrm{ml}$ on FACSCalibur cell-sorting machine. The data were analyzed by CellQuestPro software, which was provided with the machine.

\section{Spermatozoa count}

Spermatozoa counts were conducted according to an established protocol [98]. Briefly, the mice were euthanized, and the epididymis was dissected, rapidly frozen in liquid nitrogen and stored at $-80^{\circ} \mathrm{C}$ until the sperm heads were counted as follows. The organ was first cut with a scalpel into several fragments and homogenized in $50 \mathrm{ml}$ $0.15 \mathrm{M} \mathrm{NaCl}$ containing $0.005 \%$ (vol/vol) Triton X-100 (Sigma). After homogenization with three rounds of sonication $(12 \mathrm{kHz})$, an aliquot of the cell suspension was loaded onto a Malassez hemocytometer, and spermatozoa heads were counted. The data from at least ten controls or ATZ-treated animals were averaged and plotted; a $t$-test was then conducted using Excel software.

\section{Quantitative PCR and microarray experiments}

Total RNA was prepared using TRIzol reagent (Life Technologies). Reverse transcription of total RNA was performed using QuantiTect Reverse Transcription (Qiagen) according to the manufacturer's instructions. Quantitative PCR was performed using the ABI 7500 real-time PCR system. Relative expression values were calculated with ABI SDS software version V2.0.5. The primer sequences used in this research are indicated below. Duplicates of at least three independent experiments were used. Statistical significance was assessed by Student's $t$ test. For Affymetrix microarray experiments, RNA samples were converted to single-stranded biotin-labeled DNA, according to the GeneChip whole- 
transcript terminal labeling user's manual, and hybridized to an Affymetrix Gene-Chip mouse gene 2.0 st array. The RNA amplification, biotin labeling and hybridization, washing and scanning were carried out according to Affymetrix protocols. Differentially expressed genes were detected using AMEN software [15] with a fold-change cutoff value of 1.5 and a $p$-value $<0.05$. The qPCRquantification Chip-Seq experiments were carried out as previously described [87]. Equal amounts of ChIP and input DNA were taken for PCR. Quantitative PCR was performed using the ABI 7500 real-time PCR system. The copy number for each locus was calculated with ABI SDS software version V2.0.5 using a standard curve. Enrichments were estimated as a ratio of copy number in ChIP samples to the copy number in the input sample. The averaged values of enrichment of at least three treated samples were compared, plotted and expressed as fold change. The following primers were used for $\mathrm{qPCR}$ analysis:

\begin{tabular}{|c|c|c|}
\hline Gene symbol & $5^{\prime}->3^{\prime}$, forward & $5^{\prime}->3^{\prime}$, reverse \\
\hline Dhrs1 & CTGTTCGAGCAAGTAGATCGG & CATAAGTAGTGGCCTCTGAGTC \\
\hline Gbfi & GGTGCAAGTCCCAGGATAAA & GCAGGGTATGCATCAGGTCT \\
\hline G3bp2 & TAACAGTGGACAGCCTGAGAG & CATCTTCTGACTCTTCATCAAGTTCTG \\
\hline Kif18b & CCCAGCGACAATACTCCCTG & CCTGAAGACTTAGACTCGGAACAC \\
\hline Entpd4 & AAGCTGCCAAGGATTACTGTG & TTTGTAGGTGACAGGAAAGGAG \\
\hline Ldlr & AGGTGTGAAGATATTGACGAGTG & TGAAGAGCAGATAGCCTATGGA \\
\hline Star & TCTCTGCTTGGTTCTCAACTGG & AAACACCTTGCCCACATCTG \\
\hline $\operatorname{Rrn} 3$ & ACATCATATTGAGATTGCCCTGGT & AGAATCTGAAACATCTATGCCACCT \\
\hline Tbx 18 & GGGAGGAACAGAATGGGTTTGG & CAGGTGAGGATGTGTAGCAGG \\
\hline Fryl & GATCGCAGTCACCAGGAGCA & AAACACAACGGAGGGATTCTTGG \\
\hline Smim7 & AACTTTCCATTCTCCTGCCT & GCCTGAACTTAGACTTGACCC \\
\hline Hdac5 & GCATTCTACAACGATCCCTCTG & CACCACTGTCCTGAAGGCTG \\
\hline Huwe1 & GCAGAGAACCTCAAGTCAACCA & GCTAAGATCCCGAACAACTCCT \\
\hline Trim45 & GCTTTAACGGTAGACCACCTG & CTTCTGTCGCCTATGAGCCTG \\
\hline Mid1 & GAAGACCAACAGTCAGCCGT & GAACACGTTGCCAGCCACTC \\
\hline Ncoa2 & AAGGCGAAGATTTGCAGTCC & TGTCCAGTGAAGTGATCTTGCC \\
\hline Cyp19a1 & CTCATTATCAGCAAGTCCTCAAGCA & TAAAGAAAGGGCGAATTGTTCTCCA \\
\hline Star & TCTCTGCTTGGTTCTCAACTGG & AAACACCTTGCCCACATCTG \\
\hline Genomic differential peaks coordinates & $5^{\prime}->3^{\prime}$, forward & $5^{\prime}->3^{\prime}$, reverse \\
\hline chr2a: 57117256-57119105 & GCAGATTACCGCTAGAGAAGGA & CCAAGGGACAGAAGGGAAAGG \\
\hline chr2b:126752438-126754410 & CTTGCTGTGATGTAACAATGCCTG & AGTACCTCTTGCTGAATGAATGTG \\
\hline chr4:96197763-96198380 & AGAGGATAATTACCCTGTACTACCC & GTTCCTITCTCTGTCTTCAATTCC \\
\hline chr6a:116626598-116627142 & AGGAAGAGGACAAAGGTGGA & CAGGAAGATAAGAAGGTGAGAAGG \\
\hline chr6b:72197660-72199094 & ATTCATGCTTCCCTTCGCCT & TAACACCTACCAGAGCCAACC \\
\hline chr7:104792205-104794646 & TTAATCAGGTGCTCCCTTAAGTCAG & TGAAACAATCACCTGTCTACACCA \\
\hline chr8:74543719-74544319 & CAAGTAAGGGTGGGAGGTGAG & AATGGATGAGGCAACAGTATGAC \\
\hline chr9:54029137-54032749 & CCTGATCTTGAAATGAACCCTACCA & TACACTGTCCACTGTCTCCTCTG \\
\hline chr13a:120278317-120279418 & CCTGCAGAATGCCCAGATTAAA & CCTAAGTAAACCTGAGGTGGACT \\
\hline chr13b:32360875-32361606 & TTGGTTGGTTGATTGGTTGGT & CAGTACGAGTTCTCCTTCTATCCT \\
\hline chr16:93262599-93264142 & CTTAGAACTGGCTTGAGGTGTTGG & TGTGGAGAGGAGTGTGCTTTCAG \\
\hline chr17a:6429542-6429778 & TCTGAGGGAAGAGTAAGACATTTG & CGTGGCTTCAGAGTCTITACTT \\
\hline chr17b:91256505-91257806 & ACACCTTGGCCTGAATTTGTC & GCACACTTTCAATTTCTCTGACC \\
\hline chr19:36992713-36994298 & CGAATGAAGGCTACGGATGAG & CCTGCTAACTGAGAACACTGG \\
\hline chrX:166434738-166436029 & GCAGTCACTCATGTCATCCC & GTCGCTATGAGTGACTGCTG \\
\hline chrY:1425238-1426447 & СTCTTGATTTGTCTCCTAATTCTCC & CCTCTGTCCCTITATATGAACC \\
\hline chr5:143665170-143665301 & CACCCATCGCCAAAACTCTTCATCCT & CGCACAGTGCAGCATTITITACC \\
\hline
\end{tabular}


All Affymetrix microarray data from this study are available and have been deposited in the National Center for Biotechnology Information Gene Expression Omnibus under the following numbers:

\begin{tabular}{lll}
\hline Sample name & Title & Accession number \\
ATZ_1 & Atrazine_treated & GSM1561768 \\
ATZ_2 & Atrazine_treated & GSM1561769 \\
ATZ_3 & Atrazine_treated & GSM1561770 \\
Ctrl_1 & Control & GSM1561771 \\
Ctrl_2 & Control & GSM1561772 \\
Ctrl_3 & Control & GSM1561773 \\
\hline
\end{tabular}

\section{Antibodies}

The following commercial antibodies were used: goat antiDMC1 (sc-8973, C-20), goat anti-ATR (sc-1887, N19), mouse anti-SYCP3 (sc-74569, d-1), rat anti-GATA1 (sc265) antibodies from Santa Cruz. Rabbit anti-H3K4me3 (07-473), from Millipore, rabbit anti-SYCP3 (ab15093) from Abcam, rabbit anti- $\gamma \mathrm{H} 2 \mathrm{AX}$ from Trevigen (4411PC-100) and goat anti-PLZF (AF2944) from R\&D systems. Secondary HRP antibodies were purchased from Jackson Laboratories. Fluorescent secondary Alexa antibodies were purchased from Invitrogen.

\section{Meiotic surface spreads}

The seminiferous tubules were chopped in PBS. The cells were then released from the tubules by pipetting and were filtered through a $40-\mu \mathrm{m}$ cell strainer (Falcon). The cells were pelleted and washed with PBS. The resulting pellet was resuspended in $0.5 \%$ (wt/vol) $\mathrm{NaCl}$, added to glass slides, and allowed to adhere for 10-15 min. The slides were fixed in $2 \%$ (wt/vol) paraformaldehyde with $0.03 \%$ (wt/vol) SDS for $3 \mathrm{~min}$, then $2 \%$ (wt/vol) paraformaldehyde for $3 \mathrm{~min}$ and then washed four times in $0.4 \%$ (vol/vol) Photo-Flo 200 (Kodak) for $1 \mathrm{~min}$ and air-dried. For quantification of the different $\gamma \mathrm{H} 2 \mathrm{AX}$ staining patterns, spermatocyte preparations were analyzed from at least four ATZtreated mice and controls; at least 600 nuclei were classified according to the criteria described in the text or figure legend. For quantification of the different ATR staining patterns, at least 100 nuclei were classified according to the criteria described in the text or figure legend. We also performed surface spreads as described in a previous study [65] and compared the two methods by analyzing the proportions of cells in different substages. The methods yielded similar results.

\section{Meiotic prophase I substage analysis}

Analysis of the meiotic substages was performed according to previous studies $[50,62]$.

\section{Immunofluorescence}

The slides were incubated with blocking solution (1\% (vol/vol) donkey serum, $0.3 \%$ (wt/vol) BSA, and $0.005 \%$ ( vol/vol) Triton X-100 in PBS) for 20 min at $37{ }^{\circ} \mathrm{C}$ in a humidity chamber. The primary antibodies were diluted in blocking buffer and incubated under the same conditions for $1 \mathrm{~h}$. After two 5-min washes in $0.4 \%$ ( $\mathrm{vol} / \mathrm{vol})$ Photo-Flo/PBS solution, the slides were blocked for an additional $5 \mathrm{~min}$ and incubated with secondary antibodies for $20 \mathrm{~min}$ at room temperature. The slides were washed twice with $0.4 \%$ (vol/vol) Photo-Flo in PBS, rinsed twice with $0.4 \%$ (vol/vol) Photo-Flo, and allowed to air dry. The images were taken using an AxioImager microscope equipped with an AxioCam MRc5 camera and AxioVision software version 4.8.2 (Zeiss, Le Pecq, France) with a 63X objective lens.

\section{Chromatin immunoprecipitation and high-throughput sequencing}

Chromatin immunoprecipitation was conducted as previously described $[12,87]$, with small modifications. Testes were fixed for $10 \mathrm{~min}$ in $1 \%$ (wt/vol) formaldehyde. After quenching, the tissue was homogenized, filtered through a 40- $\mu \mathrm{m}$ cell strainer, and washed in the following buffers: 1) PBS (twice); 2) $0.25 \%$ (vol/vol) Triton X100, 10 mM EDTA, 0.5 mM EGTA, 10 mM Tris pH8; 3) $0.2 \mathrm{M} \mathrm{NaCl}, 1 \mathrm{mM}$ EDTA, $0.5 \mathrm{mM}$ EGTA, $10 \mathrm{mM}$ Tris pH8. Cells were lysed in $1.5 \mathrm{ml}$ of the lysis buffer $(1 \%$ (wt/vol) SDS, $10 \mathrm{mM}$ EDTA, and $50 \mathrm{mM}$ TrisCl pH8) with a complete protein-inhibitor cocktail (Roche), and the chromatin was sheared to $\sim 500$ bp by sonication. The sample was dialyzed against ChIP buffer $(0.01 \%$ (wt/vol) SDS, $1.1 \%$ (vol/vol) Triton X-100, $1.2 \mathrm{mM}$ EDTA, $16.7 \mathrm{mM}$ TrisHCl, $167 \mathrm{mM} \mathrm{NaCl}$ ). Chromatin was incubated with appropriate antibodies overnight at $4{ }^{\circ} \mathrm{C}$ with Dynabead beads (10002D, Invitrogen). The beads were washed in the following buffers: 1) $0.1 \%$ (wt/vol) SDS, $1 \%$ (vol/vol) Triton X-100, 2 mM EDTA, $20 \mathrm{mM}$ TrisHCl, $150 \mathrm{mM} \mathrm{NaCl}$; 2) $0.1 \%$ (wt/vol) SDS, $1 \%$ (vol/vol) Triton X-100, 2 mM EDTA, $20 \mathrm{mM}$ TrisCl pH8, $500 \mathrm{mM} \mathrm{NaCl}$; 3) $0.25 \mathrm{M} \mathrm{LiCl}, 1 \%$ (vol/vol) Igepal, $1 \mathrm{mM}$ EDTA, $10 \mathrm{mM}$ TrisCl, pH8, 1 \% (wt/vol) deoxycholic acid; 4) TE (twice). The chromatin was eluted by $1 \%$ (wt/vol) SDS, $0.1 \mathrm{M} \mathrm{NaHCO} 3 \mathrm{pH} 9$ at $65{ }^{\circ} \mathrm{C}$, and crosslinking was reversed at $65{ }^{\circ} \mathrm{C}$ for $5 \mathrm{~h}$. The DNA was deproteinized for $2 \mathrm{~h}$ with proteinase $\mathrm{K}$ and purified with a MinElute Reaction Clean-Up kit (QIAGEN). The DNA concentration was measured with a Quantus Fluoremeter (E6150, Promega) using the Quantiflor dsDNA 
system, (E2670, Promega). The libraries were prepared from $50 \mathrm{ng}$ of ChiP and input material using the NEBNext Ultra DNA library Prep Kit for Illumina (NEB \#E7370S). The library selection was conducted using excision fragments from a $2 \%$ (wt/vol) agarose gel including GelGreen stain (Gentaur, 41005); 180-220 bp fragments were excised using a Dark Reader transilluminator (Clare Chemical research, Dr-46B). An Illumina Hiseq1500 Genome Analyzer was used to perform massively parallel 50-bp sequencing in Single End mode. We sequenced two biological replicates per condition in multiplexing mode. The reads were demultiplexed and passed through quality control, at which point reads shorter than 50 nucleotides were removed. FastQ files were generated at a genomic platform in Rennes, France.

\section{Peak calling and differential-peak finding}

Between 71 and 97 millions tags were derived from anti-H3K4me3 ChIP and input. The resulting sequences were quality filtered with the Sickle program [40] with $-\mathrm{q} 33$ and mapped back to the mouse $\mathrm{mm} 9 /$ NCBI37 genome using Bowtie 1.0.0 with seed length 20 . The results were visualized in the Integrative genomics viewer IGV version 2.3.36 [95]. Only tags that passed the quality filter and mapped uniquely to the genome were used. ChIP enrichment was further verified using CHANCE [21]. The H3K4me3 mark peaks were identified using MACS 2.0.1 [24] with two biological replicate samples, including corresponding input, shift-size window $73 \mathrm{bp}$, no model, with $p$-value threshold $<10^{-5}$. Two biological replicates for each condition were analyzed independently. The set of peaks was verified at an irreproducible discovery rate (IDR) of $0.05 \%$ [46] to confirm that the samples were sufficiently similar to be used in the analysis. The number of mapped reads was multiplied by a scale factor to normalize the total number of reads in different samples. To compare the H3K4me3 CHIP datasets of ATZ-treated and control samples, differential peak calling was performed using several steps. First, from all the peaks called above, we selected the peaks that were reproducible in both datasets in the same condition. From the dataset of selected peaks, we kept only peaks with average expression values above the $5 \%$ quantile; last, we selected the peaks with fold changes above 1.5 and FDR $<5 \%$. Statistical significance was calculated using a Limma test [89]. Annotation of significant differential peaks was performed by CEAS [83]. All sequencing data from this study are publicly available and have been deposited in the National Center for Biotechnology Information Gene Expression Omnibus.
The following samples from ChIP seq data were deposited at GEO:

\begin{tabular}{lll}
\hline Sample name & Title & Accession number \\
ATZ_1 & Atrazine_treated & GSM1563221 \\
ATZ_2 & Atrazine_treated & GSM1563222 \\
Input & Atrazine_treated & GSM1563225 \\
Ctrl_1 & Control & GSM1563223 \\
Ctrl_2 & Control & GSM1563224 \\
Input & Control & GSM1563226 \\
\hline
\end{tabular}

\section{Gene Ontology (GO) term analyses}

Gene Ontology (GO) term analyses were performed using DAVID v6.7 [33] with enrichment thresholds ease 0.05, kappa index 3. Functional classification was performed with the same subset of the gene list with parameter kappa similarity 5 and initial group number 5 .

\section{Meme-ChiP motif search}

For the analysis, we used the summits of 100-bp sequences from differential peaks, excluding DSB-associated peaks. Motif finding was performed with MEME-ChIP [49] following default parameters. Identified motifs were compared with known motifs using TomTom [93] with a $q$ - value less than 0.003 .

All sequencing and Gene-Chips data from this study are publicly available and have been deposited in the National Center for Biotechnology Information Gene Expression Omnibus, GO number: GSE 64037.

\section{Additional file}

Additional file 1: Supplementary material. (PDF 2459 kb)

\section{Abbreviations}

DSB: Double-strand DNA break; PAR: Pseudoautosomal region; ATZ: Atrazine.

\section{Competing interests}

The authors declare that they have no competing interests.

\section{Authors' contributions}

FS designed the research, and AGP and FS performed the experiments. $\mathrm{CH}$ and EB performed the computational analysis of ChIP-Seq data. FC performed the Affymetrix microarray data analysis, and IS performed the protein analysis. MP and BJ participated in the experimental design and contributed to the manuscript. All authors participated in editing the manuscript. FS wrote the manuscript. All authors read and approved the final version of the manuscript.

\section{Acknowledgements}

The authors would like to thank Stephanie Kica, Marc Aubry and Florent Denoual for genome-wide sequencing at the genomic platform at University Rennes 1, Pierre-Yves Kernanec for animal care and help with dissections, and Bertrand Evard for help with production of the microarray data. This work was supported by the Chair of Excellence program from the European University of Brittany, Atip - Avenir program from INSERM; CH was supported by a fellowship from the China Scholarship Council (CSC). 


\section{Author details}

${ }^{1}$ Inserm U1085 IRSET, 263 Avenue du Général Leclerc, 35042 Rennes, France. ${ }^{2}$ EHESP, Avenue du Professeur Léon-Bernard, 35043 Rennes, France. ${ }^{3}$ Present address: University of Zagreb, Faculty of Food Technology and Biotechnology, 10000 Zagreb, Croatia.

\section{Received: 27 February 2015 Accepted: 15 October 2015} Published online: 30 October 2015

\section{References}

1. Abarikwu SO, Adesiyan AC, Oyeloja TO, Oyeyemi MO, Farombi EO. Changes in sperm characteristics and induction of oxidative stress in the testis and epididymis of experimental rats by a herbicide, atrazine. Arch Environ Contam Toxicol. 2010;58(3):874-82.

2. Abarikwu SO, Farombi EO, Pant AB. Kolaviron biflavanoids of Garcinia kola seeds protect atrazine-induced cytotoxicity in primary cultures of rat Leydig cells. Int J Toxicol. 2012;31(4):407-15.

3. Ackema KB, Hench J, Bockler S, Wang SC, Sauder U, Mergentaler H, et al. The small GTPase Arf1 modulates mitochondrial morphology and function. EMBO J. 2014:33(22):2659-75.

4. Allard P, Colaiacovo MP. Bisphenol A impairs the double-strand break repair machinery in the germline and causes chromosome abnormalities. Proc Natl Acad Sci U S A. 2010;107(47):20405-10.

5. Babic-Gojmerac T, Kniewald Z, Kniewald J. Testosterone metabolism in neuroendocrine organs in male rats under atrazine and deethylatrazine influence. J Steroid Biochem. 1989:33(1):141-6.

6. Baker CL, Walker M, Kajita S, Petkov PM, Paigen K. PRDM9 binding organizes hotspot nucleosomes and limits Holliday junction migration. Genome Res. 2014;24(5):724-32

7. Bardullas U, Giordano M, Rodriguez VM. Chronic atrazine exposure causes disruption of the spontaneous locomotor activity and alters the striatal dopaminergic system of the male Sprague-Dawley rat. Neurotoxicol Teratol. 2011:33(2):263-72.

8. Basini G, Bianchi F, Bussolati S, Baioni L, Ramoni R, Grolli S, et al. Atrazine disrupts steroidogenesis, VEGF and NO production in swine granulosa cells. Ecotoxicol Environ Saf. 2012;85:59-63.

9. Bayrer JR, Mukkamala S, Sablin EP, Webb P, Fletterick RJ. Silencing LRH-1 in colon cancer cell lines impairs proliferation and alters gene expression programs. Proc Natl Acad Sci U S A. 2015;112(8):2467-72.

10. Bhatti JS, Sidhu IP, Bhatti GK. Ameliorative action of melatonin on oxidative damage induced by atrazine toxicity in rat erythrocytes. Mol Cell Biochem. 2011:353(1-2):139-49.

11. Blahova J, Plhalova L, Hostovsky M, Divisova L, Dobsikova R, Mikulikova I, et al. Oxidative stress responses in zebrafish Danio rerio after subchronic exposure to atrazine. Food Chem Toxicol. 2013;61:82-5.

12. Brick K, Smagulova F, Khil P, Camerini-Otero RD, Petukhova GV. Genetic recombination is directed away from functional genomic elements in mice. Nature. 2012:485(7400):642-5.

13. Brower JV, Lim CH, Jorgensen M, Oh SP, Terada N. Adenine nucleotide translocase 4 deficiency leads to early meiotic arrest of murine male germ cells. Reproduction. 2009:138(3):463-70.

14. Campos-Pereira FD, Oliveira CA, Pigoso AA, Silva-Zacarin EC, Barbieri R, Spatti EF, et al. Early cytotoxic and genotoxic effects of atrazine on Wistar rat liver: a morphological, immunohistochemical, biochemical, and molecular study. Ecotoxicol Environ Saf. 2012;78:170-7.

15. Chalmel F, Primig M. The Annotation, Mapping, Expression and Network (AMEN) suite of tools for molecular systems biology. BMC Bioinformatics. 2008;9:86.

16. Chevrier C, Limon G, Monfort C, Rouget F, Garlantezec R, Petit C, et al. Urinary biomarkers of prenatal atrazine exposure and adverse birth outcomes in the PELAGIE birth cohort. Environ Health Perspect. 2011;119(7):1034-41.

17. Cooper RL, Stoker TE, Goldman JM, Parrish MB, Tyrey L. Effect of atrazine on ovarian function in the rat. Reprod Toxicol. 1996;10(4):257-64.

18. Crain DA, Guillette Jr LJ, Rooney AA, Pickford DB. Alterations in steroidogenesis in alligators (Alligator mississippiensis) exposed naturally and experimentally to environmental contaminants. Environ Health Perspect. 1997;105(5):528-33.

19. Dalton RL, Pick FR, Boutin C, Saleem A. Atrazine contamination at the watershed scale and environmental factors affecting sampling rates of the polar organic chemical integrative sampler (POCIS). Environ Pollut. 2014;189:134-42.
20. Date S, Nozawa O, Inoue H, Hidema S, Nishimori K. Impairment of pachytene spermatogenesis in Dmrt7 deficient mice, possibly causing meiotic arrest Biosci Biotechnol Biochem. 2012;76(9):1621-6.

21. Diaz A, Nellore A, Song JS. CHANCE: comprehensive software for quality control and validation of ChIP-seq data. Genome Biol. 2012;13(10):R98.

22. Fa S, Pogrmic-Majkic K, Samardzija D, Glisic B, Kaisarevic S, Kovacevic R, et al. Involvement of ERK1/2 signaling pathway in atrazine action on FSH-stimulated LHR and CYP19A1 expression in rat granulosa cells. Toxicol Appl Pharmacol. 2013;270(1):1-8.

23. Fan W, Yanase T, Morinaga $H$, Gondo S, Okabe T, Nomura M, et al. Herbicide atrazine activates SF-1 by direct affinity and concomitant co-activators recruitments to induce aromatase expression via promoter $\|$. Biochem Biophys Res Commun. 2007;355(4):1012-8.

24. Feng J, Liu T, Qin B, Zhang Y, Liu XS. Identifying ChIP-seq enrichment using MACS. Nat Protoc. 2012;7(9):1728-40.

25. Gojmerac T, Kartal B, Zuric M, Curic S, Mitak M. Serum biochemical and histopathological changes related to the hepatic function in pigs following atrazine treatment. J Appl Toxicol. 1995;15(3):233-6.

26. Hall $H$, Hunt $P$, Hassold T. Meiosis and sex chromosome aneuploidy: how meiotic errors cause aneuploidy; how aneuploidy causes meiotic errors. Curr Opin Genet Dev. 2006:16(3):323-9.

27. Hayashi K, Yoshida K, Matsui Y. A histone H3 methyltransferase controls epigenetic events required for meiotic prophase. Nature. 2005;438(7066):374-8.

28. Hayes T, Haston K, Tsui M, Hoang A, Haeffele C, Vonk A. Herbicides: feminization of male frogs in the wild. Nature. 2002;419(6910):895-6.

29. Hayes T, Haston K, Tsui M, Hoang A, Haeffele C, Vonk A. Atrazine-induced hermaphroditism at $0.1 \mathrm{ppb}$ in American leopard frogs (Rana pipiens): laboratory and field evidence. Environ Health Perspect. 2003;111(4):568-75.

30. Hayes TB, Collins A, Lee M, Mendoza M, Noriega N, Stuart AA, et al. Hermaphroditic, demasculinized frogs after exposure to the herbicide atrazine at low ecologically relevant doses. Proc Natl Acad Sci U S A. 2002;99(8):5476-80.

31. Hecker M, Park JW, Murphy MB, Jones PD, Solomon KR, Van Der Kraak G, et al. Effects of atrazine on CYP19 gene expression and aromatase activity in testes and on plasma sex steroid concentrations of male African clawed frogs (Xenopus laevis). Toxicol Sci. 2005;86(2):273-80.

32. Henderson KA, Keeney S. Tying synaptonemal complex initiation to the formation and programmed repair of DNA double-strand breaks. Proc Natl Acad Sci U S A. 2004;101(13):4519-24.

33. Huang da W, Sherman BT, Lempicki RA. Systematic and integrative analysis of large gene lists using DAVID bioinformatics resources. Nat Protoc. 2009:4(1):44-57.

34. Hunt PA, Koehler KE, Susiarjo M, Hodges CA, llagan A, Voigt RC, et al. Bisphenol a exposure causes meiotic aneuploidy in the female mouse. Curr Biol. 2003;13(7):546-53

35. Ishibashi S, Brown MS, Goldstein JL, Gerard RD, Hammer RE, Herz J. Hypercholesterolemia in low density lipoprotein receptor knockout mice and its reversal by adenovirus-mediated gene delivery. J Clin Invest. 1993;92(2):883-93.

36. Islam MO, Hara M, Miyake J. Induction of P-glycoprotein, glutathione-S-transferase and cytochrome P450 in rat liver by atrazine. Environ Toxicol Pharmacol. 2002;12(1):1-6

37. Jackson SP. Sensing and repairing DNA double-strand breaks. Carcinogenesis. 2002;23(5):687-96.

38. Jin $Y$, Lin X, Miao W, Wang L, Wu Y and Fu Z. "Oral exposure of pubertal male mice to endocrine-disrupting chemicals alters fat metabolism in adult livers." Environ Toxicol. 2014. doi: 10.1002/tox.22013

39. Jin $Y$, Wang L, Chen G, Lin X, Miao W, Fu Z. Exposure of mice to atrazine and its metabolite diaminochlorotriazine elicits oxidative stress and endocrine disruption. Environ Toxicol Pharmacol. 2014;37(2):782-90.

40. Joshi NA, Fass JN. "Sickle: A sliding-window, adaptive, quality-based trimming tool for FastQ files (Version 1.33) [Software]". 2011. https:// github.com/najoshi/sickle.

41. Juliani CC, Silva-Zacarin EC, Santos DC, Boer PA. Effects of atrazine on female Wistar rats: morphological alterations in ovarian follicles and immunocytochemical labeling of $90 \mathrm{kDa}$ heat shock protein. Micron. 2008;39(5):607-16.

42. Kauppi L, Barchi M, Baudat F, Romanienko PJ, Keeney S, Jasin M. Distinct properties of the $X Y$ pseudoautosomal region crucial for male meiosis. Science. 2011;331(6019):916-20. 
43. Keshk WA, Soliman NA, Abo El-Noor MM, Wahdan AA, Shareef MM. Modulatory effects of curcumin on redox status, mitochondrial function, and caspace-3 expression during atrazin-induced toxicity. J Biochem Mol Toxicol. 2014:28(8):378-85.

44. Kouzarides T. Chromatin modifications and their function. Cell. 2007;128(4):693-705

45. Larkin DM, Pape G, Donthu R, Auvil L, Welge M, Lewin HA. Breakpoint regions and homologous synteny blocks in chromosomes have different evolutionary histories. Genome Res. 2009;19(5):770-7.

46. Li Q, Brown JB, Huang H, Bickel P. Measuring reproducibility of high-throughput experiments. Ann Appl Stat. 2011;5:1752-79.

47. Lim S, Ahn SY, Song IC, Chung MH, Jang HC, Park KS, et al. Chronic exposure to the herbicide, atrazine, causes mitochondrial dysfunction and insulin resistance. PLoS One. 2009:4(4):e5186.

48. Liu C, Duan W, Li R, Xu S, Zhang L, Chen C, et al. Exposure to bisphenol A disrupts meiotic progression during spermatogenesis in adult rats through estrogen-like activity. Cell Death Dis. 2013;4:e676.

49. Machanick P, Bailey TL. MEME-ChIP: motif analysis of large DNA datasets. Bioinformatics. 2011;27(12):1696-7.

50. Mahadevaiah SK, Turner JM, Baudat F, Rogakou EP, de Boer P, Blanco-Rodriguez J, et al. Recombinational DNA double-strand breaks in mice precede synapsis. Nat Genet. 2001;27(3):271-6.

51. Manikkam M, Tracey R, Guerrero-Bosagna C, Skinner MK. "Pesticide and insect repellent mixture (permethrin and DEET) induces epigenetic transgenerational inheritance of disease and sperm epimutations.". Reprod Toxicol. 2012;34:708.

52. McMullin TS, Andersen ME, Nagahara A, Lund TD, Pak T, Handa RJ, et al. Evidence that atrazine and diaminochlorotriazine inhibit the estrogen/progesterone induced surge of luteinizing hormone in female Sprague-Dawley rats without changing estrogen receptor action. Toxicol Sci. 2004;79(2):278-86.

53. Mihola O, Trachtulec Z, Vlcek C, Schimenti JC, Forejt J. A mouse speciation gene encodes a meiotic histone $\mathrm{H} 3$ methyltransferase. Science. 2009;323(5912):373-5.

54. Moldovan GL, Dejsuphong D, Petalcorin MI, Hofmann K, Takeda S, Boulton SJ, et al. Inhibition of homologous recombination by the PCNA-interacting protein PARI. Mol Cell. 2012;45(1):75-86.

55. Mu H, Zhang P, Xu J. Testicular toxicity and mechanisms of chlorotoluron compounds in the mouse. Toxicol Mech Methods. 2008;18(5):399-403.

56. Murnik MR, Nash CL. Mutagenicity of the triazine herbicides atrazine, cyanazine, and simazine in Drosophila melanogaster. J Toxicol Environ Health. 1977;3(4):691-7

57. Musio A, Sbrana I. Aphidicolin-sensitive specific common fragile sites: a biomarker of exposure to pesticides. Environ Mol Mutagen. 1997;29(3):250-5.

58. Nakanishi Y, Shiratsuchi A. Phagocytic removal of apoptotic spermatogenic cells by Sertoli cells: mechanisms and consequences. Biol Pharm Bull. 2004:27(1):13-6.

59. Nodler K, Licha T, Voutsa D. Twenty years later-atrazine concentrations in selected coastal waters of the Mediterranean and the Baltic Sea. Mar Pollut Bull. 2013:70(1-2):112-8.

60. O'Hagan HM, Mohammad HP, Baylin SB. Double strand breaks can initiate gene silencing and SIRT1-dependent onset of DNA methylation in an exogenous promoter CpG island. PLoS Genet. 2008;4(8):e1000155.

61. Ochoa-Acuna H, Frankenberger J, Hahn L, Carbajo C. Drinking-water herbicide exposure in Indiana and prevalence of small-for-gestational-age and preterm delivery. Environ Health Perspect. 2009;117(10):1619-24.

62. Page J, de la Fuente R, Manterola M, Parra MT, Viera A, Berrios S, et al. Inactivation or non-reactivation: what accounts better for the silence of sex chromosomes during mammalian male meiosis? Chromosoma. 2012;121(3):307-26.

63. Papoulias DM, Tillitt DE, Talykina MG, Whyte JJ, Richter CA. Atrazine reduces reproduction in Japanese medaka (Oryzias latipes). Aquat Toxicol. 2014;154:230-9.

64. Pasqualato S, Renault L, Cherfils J. Arf, Arl, Arp and Sar proteins: a family of GTP-binding proteins with a structural device for 'front-back' communication. EMBO Rep. 2002;3(11):1035-41.

65. Peters AH, Plug AW, van Vugt MJ, de Boer P. A drying-down technique for the spreading of mammalian meiocytes from the male and female germline. Chromosome Res. 1997;5(1):66-8.

66. Pezzi V, Sirianni R, Chimento A, Maggiolini M, Bourguiba S, Delalande C, et al. Differential expression of steroidogenic factor-1/adrenal 4 binding protein and liver receptor homolog-1 (LRH-1)/fetoprotein transcription factor in the rat testis: $\mathrm{LRH}-1$ as a potential regulator of testicular aromatase expression. Endocrinology. 2004;145(5):2186-96.
67. Pogrmic K, Fa S, Dakic V, Kaisarevic S, Kovacevic R. Atrazine oral exposure of peripubertal male rats downregulates steroidogenesis gene expression in Leydig cells. Toxicol Sci. 2009;111(1):189-97.

68. Pogrmic-Majkic K, Fa S, Dakic V, Kaisarevic S, Kovacevic R. Upregulation of peripubertal rat Leydig cell steroidogenesis following $24 \mathrm{~h}$ in vitro and in vivo exposure to atrazine. Toxicol Sci. 2010;118(1):52-60.

69. Prasad TA, Reddy DC. Atrazine toxicity on hydromineral balance of fish, Tilapia mossambicus. Ecotoxicol Environ Saf. 1994:28(3):313-6.

70. Privalle CT, Crivello JF, Jefcoate CR. Regulation of intramitochondrial cholesterol transfer to side-chain cleavage cytochrome P-450 in rat adrenal gland. Proc Natl Acad Sci U S A. 1983;80(3):702-6.

71. Privalle $C T$, McNamara BC, Dhariwal MS, Jefcoate CR. ACTH control of cholesterol side-chain cleavage at adrenal mitochondrial cytochrome P-450scc. Regulation of intramitochondrial cholesterol transfer. Mol Cell Endocrinol. 1987;53(1-2):87-101.

72. Radovic T, Grujic S, Petkovic A, Dimkic M, Lausevic M. Determination of pharmaceuticals and pesticides in river sediments and corresponding surface and ground water in the Danube River and tributaries in Serbia. Environ Monit Assess. 2015;187(1):4092.

73. Raverdeau M, Gely-Pernot A, Feret B, Dennefeld C, Benoit G, Davidson I, et al. Retinoic acid induces Sertoli cell paracrine signals for spermatogonia differentiation but cell autonomously drives spermatocyte meiosis. Proc Natl Acad Sci U S A. 2012;109(41):16582-7.

74. Rodriguez I, Ody C, Araki K, Garcia I, Vassalli P. An early and massive wave of germinal cell apoptosis is required for the development of functional spermatogenesis. EMBO J. 1997;16(9):2262-70.

75. Royo H, Prosser H, Ruzankina Y, Mahadevaiah SK, Cloutier JM, Baumann M, et al. ATR acts stage specifically to regulate multiple aspects of mammalian meiotic silencing. Genes Dev. 2013;27(13):1484-94.

76. Russell LD. Histological and histopathological evaluation of the testis. Clearwater: Cache River Press; 1990.

77. Sanderson JT, Seinen W, Giesy JP, van den Berg M. 2-Chloro-s-triazine herbicides induce aromatase (CYP19) activity in H295R human adrenocortical carcinoma cells: a novel mechanism for estrogenicity? Toxicol Sci. 2000;54(1):121-7.

78. Santa Maria C, Moreno J, Lopez-Campos JL. Hepatotoxicity induced by the herbicide atrazine in the rat. J Appl Toxicol. 1987;7(6):373-8.

79. Sbrana I, Musio A. Enhanced expression of common fragile site with occupational exposure to pesticides. Cancer Genet Cytogenet. 1995;82(2):123-7.

80. Schafer FQ, Buettner GR. Redox environment of the cell as viewed through the redox state of the glutathione disulfide/glutathione couple. Free Radic Biol Med. 2001;30(11):1191-212.

81. Sharma RK, Fulia A, Chauhan PK. Antioxidant attenuation of atrazine induced histopathological changes in testicular tissue of goat in vitro. Toxicol Int. 2012:19(3):260-6.

82. Sharma S, Sarkar J, Haldar C, Sinha S. Melatonin Reverses Fas, E2F-1 and Endoplasmic Reticulum Stress Mediated Apoptosis and Dysregulation of Autophagy Induced by the Herbicide Atrazine in Murine Splenocytes. PLoS One. 2014;9(9):e108602.

83. Shin H, Liu T, Manrai AK, Liu XS. CEAS: cis-regulatory element annotation system. Bioinformatics. 2009;25(19):2605-6.

84. Simpson ER, Jefcoate CR, Brownie AC, Boyd GS. The effect of ether anaesthesia stress on cholesterol-side-chain cleavage and cytochrome P450 in rat-adrenal mitochondria. Eur J Biochem. 1972;28(3):442-50.

85. Singh $M$, Sandhir R, Kiran R. Oxidative stress induced by atrazine in rat erythrocytes: mitigating effect of vitamin E. Toxicol Mech Methods. 2010;20(3):119-26.

86. Smagulova F, Brick K, Pu Y, Sengupta U, Camerini-Otero RD, Petukhova GV. Suppression of genetic recombination in the pseudoautosomal region and at subtelomeres in mice with a hypomorphic Spo11 allele. BMC Genomics. 2013;14:493

87. Smagulova F, Gregoretti IV, Brick K, Khil P, Camerini-Otero RD, Petukhova GV. Genome-wide analysis reveals novel molecular features of mouse recombination hotspots. Nature. 2011;472(7343):375-8.

88. Smith Dl, Zhu Y, McAvoy S, Kuhn R. Common fragile sites, extremely large genes, neural development and cancer. Cancer Lett. 2006;232(1):48-57.

89. Smyth GK, Speed T. Normalization of cDNA microarray data. Methods. 2003;31(4):265-73.

90. Stouder C, Paoloni-Giacobino A. Transgenerational effects of the endocrine disruptor vinclozolin on the methylation pattern of imprinted genes in the mouse sperm. Reproduction. 2010;139(2):373-9. 
91. Suzawa M, Ingraham HA. The herbicide atrazine activates endocrine gene networks via non-steroidal NR5A nuclear receptors in fish and mammalian cells. PLoS One. 2008;3(5):e2117.

92. Tagert ML, Massey JH, Shaw DR. Water quality survey of Mississippi's Upper Pearl River. Sci Total Environ. 2014;481:564-73.

93. Tanaka E, Bailey T, Grant CE, Noble WS, Keich U. Improved similarity scores for comparing motifs. Bioinformatics. 2011;27(12):1603-9.

94. Thornton BJ, Elthon TE, Cerny RL, Siegfried BD. Proteomic analysis of atrazine exposure in Drosophila melanogaster (Diptera: Drosophilidae). Chemosphere. 2010;81(2):235-41.

95. Thorvaldsdottir H, Robinson JT, Mesirov JP. Integrative Genomics Viewer (IGV): high-performance genomics data visualization and exploration. Brief Bioinform. 2013:14(2):178-92.

96. Trentacoste SV, Friedmann AS, Youker RT, Breckenridge CB, Zirkin BR. Atrazine effects on testosterone levels and androgen-dependent reproductive organs in peripubertal male rats. J Androl. 2001;22(1):142-8.

97. Turner JM, Aprelikova O, Xu X, Wang R, Kim S, Chandramouli GV, et al. BRCA1, histone H2AX phosphorylation, and male meiotic sex chromosome inactivation. Curr Biol. 2004;14(23):2135-42.

98. Vallet-Erdtmann V, Tavernier G, Contreras JA, Mairal A, Rieu C, Touzalin AM, et al. The testicular form of hormone-sensitive lipase HSLtes confers rescue of male infertility in HSL-deficient mice. J Biol Chem. 2004:279(41):42875-80.

99. Veaute X, Jeusset J, Soustelle C, Kowalczykowski SC, Le Cam E, Fabre F. The Srs2 helicase prevents recombination by disrupting Rad51 nucleoprotein filaments. Nature. 2003;423(6937):309-12.

100. Vermeulen M, Eberl HC, Matarese F, Marks H, Denissov S, Butter F, et al. Quantitative interaction proteomics and genome-wide profiling of epigenetic histone marks and their readers. Cell. 2010;142(6):967-80.

101. Victor-Costa AB, Bandeira SM, Oliveira AG, Mahecha GA, Oliveira CA. Changes in testicular morphology and steroidogenesis in adult rats exposed to Atrazine. Reprod Toxicol. 2010;29(3):323-31.

102. Vonberg D, Hofmann D, Vanderborght J, Lelickens A, Koppchen S, Putz T, et al. Atrazine soil core residue analysis from an agricultural field 21 years after its ban. J Environ Qual. 2014;43(4):1450-9.

103. Vonberg D, Vanderborght J, Cremer N, Putz T, Herbst M, Vereecken H. 20 years of long-term atrazine monitoring in a shallow aquifer in western Germany. Water Res. 2014;50:294-306.

104. Wilhelms KW, Cutler SA, Proudman JA, Carsia RV, Anderson LL, Scanes CG. Lack of effects of atrazine on estrogen-responsive organs and circulating hormone concentrations in sexually immature female Japanese quail (Coturnix coturnix japonica). Chemosphere. 2006;65(4):674-81.

105. Youds JL, Mets DG, Mcllwraith MJ, Martin JS, Ward JD, Oneil NJ, et al. RTEL-1 enforces meiotic crossover interference and homeostasis. Science. 2010;327(5970):1254-8

106. Zhang $\mathrm{H}$, Freudenreich $\mathrm{CH}$. An AT-rich sequence in human common fragile site FRA16D causes fork stalling and chromosome breakage in S. cerevisiae. Mol Cell. 2007;27(3):367-79.

107. Zhao S, Fung-Leung WP, Bittner A, Ngo K, Liu X. Comparison of RNA-Seq and microarray in transcriptome profiling of activated T cells. PLoS One. 2014:9(1):e78644

\section{Submit your next manuscript to BioMed Central and take full advantage of:}

- Convenient online submission

- Thorough peer review

- No space constraints or color figure charges

- Immediate publication on acceptance

- Inclusion in PubMed, CAS, Scopus and Google Scholar

- Research which is freely available for redistribution

Submit your manuscript at www.biomedcentral.com/submit 